\title{
دور برامج الصحافة الاستقصائية التلفزيونية في تثكيل معارف الشباب الجامعي نحو قضية الإرهاب.
}

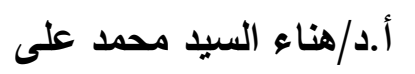

أستاذ الإعلام المساعد بكلية التربية النوعية

جامعة المنوفية

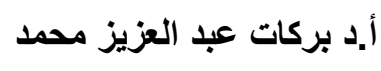

أستاذ الإذاعة والتلفزيون بكلية الإعلام الد بريز مجلد

جامعة القاهرة

دعاء هشام جمعه فرحات

باحثة دكتوراه بقسم الإعلام التربوى دماء فئمات

بكلية النربية النوعية - جامعة المنوفية

ملخص الدراسة باللغة العربية:

تهدف الدراسة الحالية إلي التعرف علي دور برامج الصحافة الاستقصائية التلفزيونية في تتكيل معارف الثباب الجامعي نحو قضية الإرهاب، وتتنمي هذه الدراسة إلي الدراسات

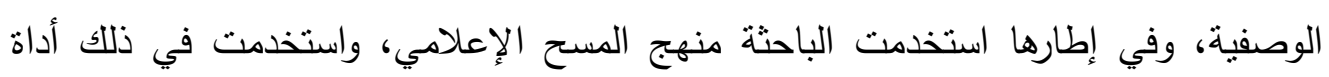

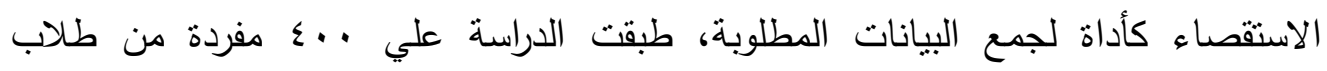
الجامعات الخاصة والحكومية فى الوجه البحري والوجه القبلي. وقد توصلت الاراسة إلي مجموعة من النتائج أهمها:

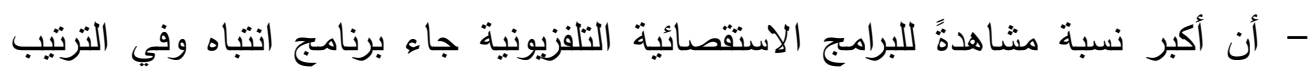

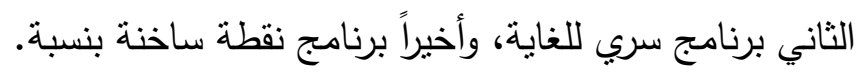

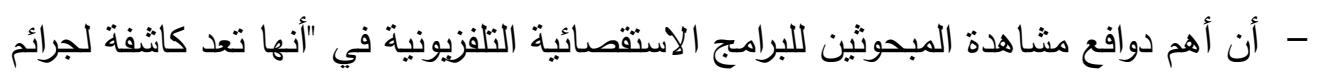

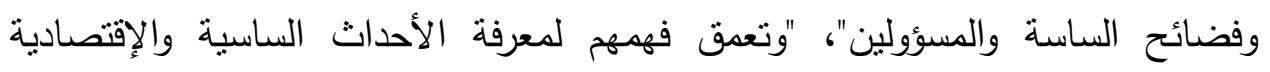

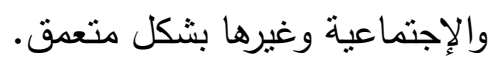
- - جاءت التفجيرات الإرهابية في مقدمة صور الإرهاب، يليها في الترتيب الثاني الإغتيالات السياسية، يليها احتجاز الرهائن ثم الإرهاب النووي.

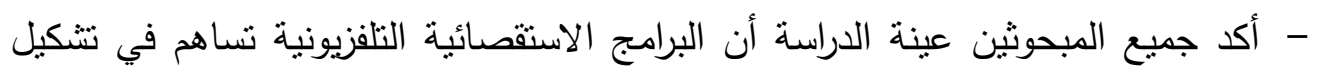
معارف المبحوثين نحو قضية الإرهاب.

- جاءت عبارة "جريئة في نتاول مختلف القضايا والأحداث" في الترتيب الأول ضمن عبارات المكون المعرفي، وجاءت عبارة "أحيانا أثنعر بحاجة إلي الاندماج مع المجتمع ومحاولة 
أن اكون عنصر إيجابي فعال في المجتمع" في الترتيب الأول ضمن عبارات المكون الوجداني، وجاءت عبارة " تدفعني إلي البحث عن برامج تعرض الحقائق التي خفيت فئ عمداً

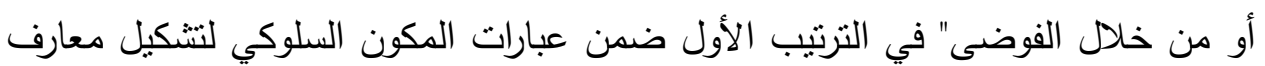

$$
\text { الثباب الجامعي نحو قضيية الإرهاب. }
$$

الكلمات المفتاحية Key Words:

T.V Investigating journalism programmesبرامج الصحافة الاستقصائية التلفزيونية The university youth الثباب الجامعي قضية الإرهاب Terrorism issue

\section{Summary of Study}

The study aims to identifying the role of the TV investigating journalism programmes in shaping the knowledge of the university youth about terrorism. This study belongs to the descriptive studies. In this study, the researcher used the media survey method. The survey tool was used as a tool to collect the required data of private and government universities in Upper Egypt and Upper Egypt.

\section{Results:}

- The biggest viewing rate for TV investigating journalism programmes was the Entbah programme and in the second ranking a Top secret programme, and finally a hot spot programme.

- the main motivations for viewing television programme respondents are that they are "revealing the crimes and scandals of politicians and officials" and "deepening their understanding of political, economic, social and other events in depth.

- Terrorist bombings came in the forefront of terrorism, followed by political assassinations, followed by hostage-taking and nuclear terrorism.

- All respondents confirmed that TV investigating journalism programmes contribute to the formation of the knowledge of the respondents on the issue of terrorism.

- The phrase "bold in dealing with various issues and events" came in the first order within the terms of the cognitive component. "Sometimes I feel I need to integrate with society and try to be an active positive element in society" in the first order in terms of the emotional component. To search for programs showing the facts that were intentionally or through chaos "in the first order within the terms of the behavioral component to form the knowledge of university youth towards the issue of terrorism. 


\section{مدخل الاراسة:}

تعد وسائل الإعلام عامل فعال ومهم في التأثير في حباة الأفراد والثعوب وتوجهاتهم

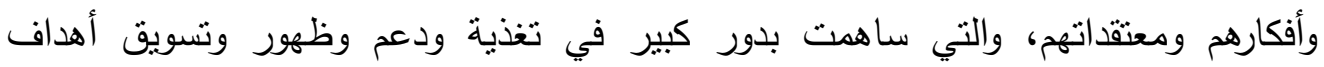
وغايات العنف والإرهاب والتطرف، كما أن التطور المذهل لوسائل الإعلام في العقود الأخيرة،

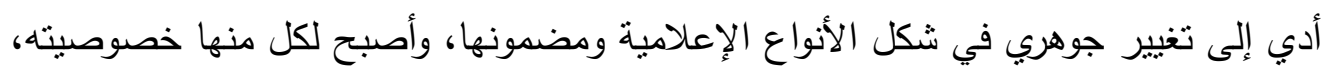
التي أسهمت في تقدمه، مما أدى إلي ظهور الصحافة الاستقصائية التلفزيونية كنوع إعلامي

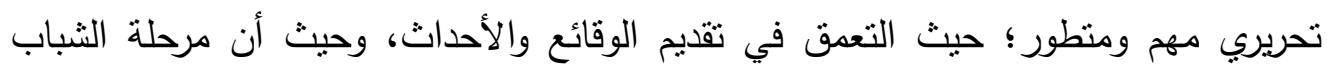

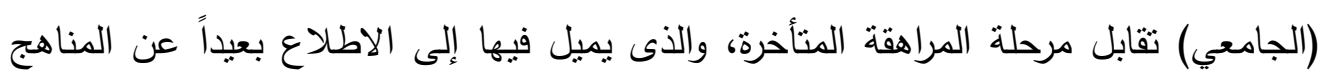

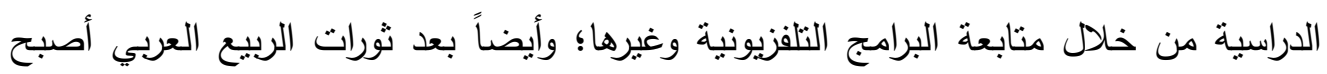

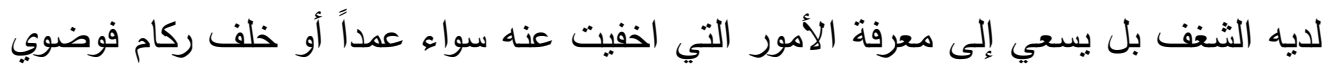

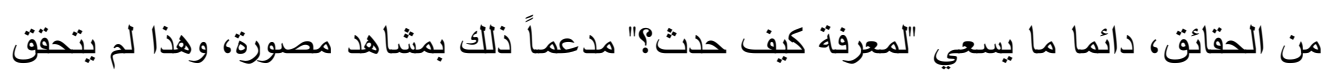
إلا من خلال الصحافة الاستقصائية التلفزيونية.

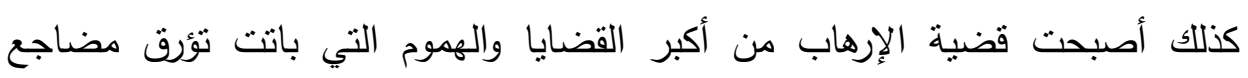

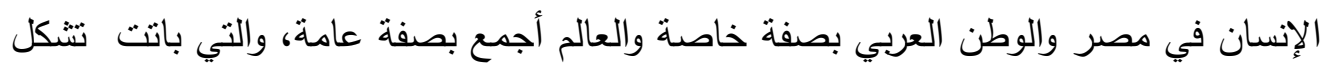

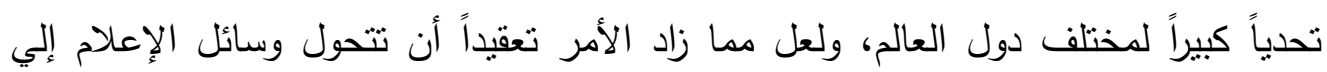
وسائل دعائية للمنظمات الإرهابية، فالعلاقة بين وسال الإعلام والإرهاب علاقة نكاملية Symbiotic relationship الإرهابيين بنشر أقوالهم وأفعالهم وتضخيم قوتهم من دون قصد، ليعطي بذللك للإرهاب صدي إعلامياً واسعاً. مشكلة الاراسة: يمكن بلورة مشكلة الدراسة فى الإجابة عن التساؤل التالى:

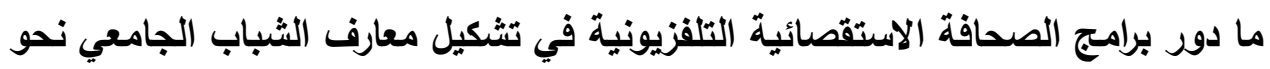
قضية الإرهاب؟

- ما معدل مشاهدة الثباب الجامعي لبرامج الصحافة الاستقصائية التلفزيونية؟

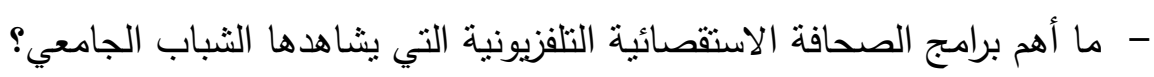
- ما معدل مشاهدة الثباب الجامعي لقضية الإرهاب في برامج الصحافة الاستقصائية

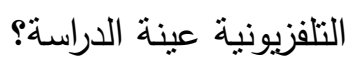


- ما دوافع مشاهدة الثباب الجامعي لقضية الإرهاب ببرامج الصحافة الاسنقصائية

التلفزيونية؟

- إلى أي مدى تساهم برامج الصحافة الاستقصائية في تشكيل معارف الثباب الجامعي بقضية الإرهاب؟

- ما العلاقة بين اهتمام برامج الصحافة الاستقصائية التلفزيونية بقضية الارهاب ومدى اهتمام الثباب بتلك القضية؟ مانه - ماهي أكثر صور الإرهاب ببرامج الصحافة الاسقصائية التلفزيونية من وجهة نظر الثباب الجامعي

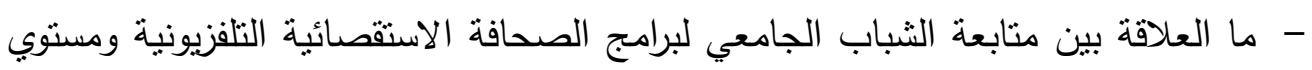

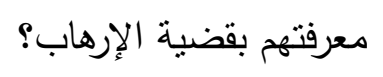

أهمية الدراسة:

نستمد هذه الدراسة أهميتها من ندرة الدراسات السابقة التي أجريت حول برامج الصحافة الاستقصائية التلفزيونية نظراً لحداثة هذه النوعية من البرامج، كما تعد هذه الدراسة من أوائل

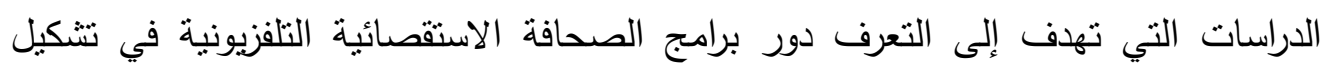
معارف الثباب الجامعي نحو قضية الإرهاب، وبناء على ما سبق فإن أهمية الدراسة تتمثل في:

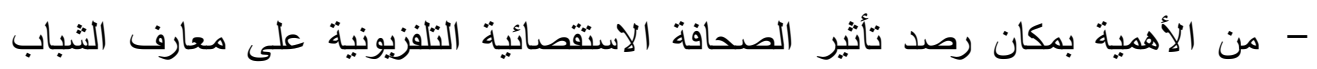
الجامعي نحو قضية الإرهاب، والذى قد يسهم فى التعرف على المحتوى المعرفي والثقافي

$$
\text { المقدم للشباب الجامعي عن تلك القضية. }
$$

- - تضع أيدينا على طبيعة الدور الفعلي الذي تقوم به برامج الصحافة الاستقصائية التلفزيونية فى تشكيل معارف الثباب الجامعي نحو قضية الإرهاب.

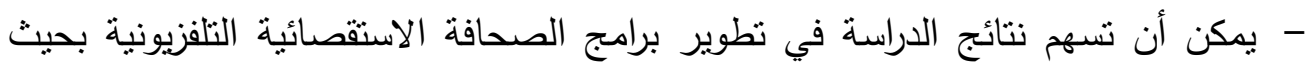

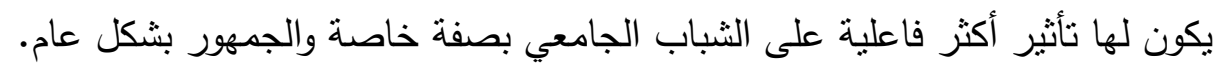
- يمكن أن تسهم نتائج هذه الدراسة في معرفة العلاقة بين دور برامج الصحافة الاستقصائية التلفزيونية في تشكيل معارف الثباب الجامعي نحو قضية الإرهاب. أهداف الدراسة:

تهدف الدراسة الحالية إلي التعرف علي دور برامج الصحافة الاستقصائية التلفزيونية فى تشكيل معارف الشباب الجامعي نحوها، وذلك من خلال: 
- التعرف على معدل مشاهدة الثباب الجامعي لبرامج الصحافة الاستقصائية التلفزيونية في البرامج عينة الدراسة.

- التعرف على معدل تعرض الثباب الجامعي لقضية الإرهاب في برامج الصحافة الاستقصائية التلفزيونية عينة الدراسة.

- التعرف علي العلاقة بين معدل متابعة المبحوثين لقضية الإرهاب ببرامج الصحافة الاستقصائية التلفزيونية وتشكيل معارفهم نحوها.

- الكثف عن مدي اعتماد الثباب الجامعي على برامج الصحافة الاستقصائية التلفزيونية كمصدر لنتكيل المعارف حول قضية الإرهاب. - الكثف عن دوافع منابعة الثباب الجامعي لقضية الإرهاب في برامج الصحافة الاستقصائية التلفزيونية. - التعرف على مستوي معرفة الثباب الجامعي بقضية الإرهاب التي تتتاولها برامج الصحافة الاستقصائية التلفزيونية. مصطلحات الاراسة: الصحافة الاستقصائية التلفزيونية: نمط من العمل الإعلامي الذي يتميز بالبحث والتتقيب عن

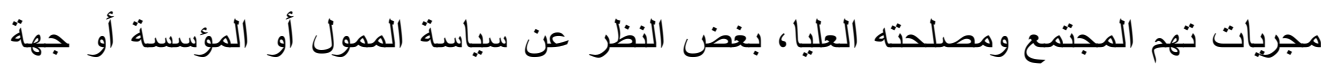

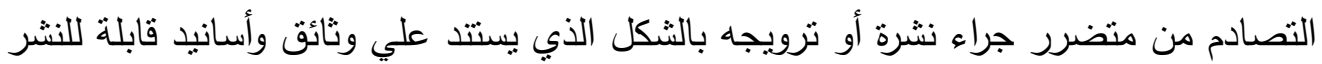
والعرض (')

قضية الإرهاب: كل فعل من أفعال العنف أو التهديد، أياً كان بواعثه وأغراضه، يقع تتفيذاً

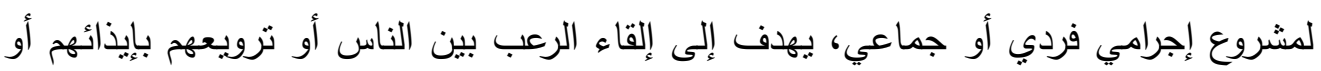

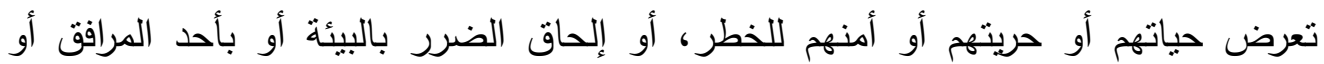
الأملاك العامة أو الخاصة أو اختلاسها أو الاستلاء عليها. (؟)

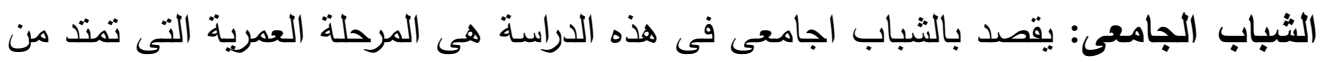
1):آسنة، وتعتبر هذه المرحلة من أهم المراحل التي يمر بها الفرد، حيث تبدأ شخصية الإنسان بالتبلور (†)، وتتضج معالم هذه الثخصية من خلال ما يكتسبه الفرد من مهارات ومعارف. حدود الدراسة: تتمنل حدود الدراسة فيما يلي: حدود موضوعية: تتمثل في تعرض الثباب الجامعي لقضية الإرهاب ببرامج الصحافة الاستقصائية التلفزيونية ودورها فى تشكيل معارفه نحوها. 


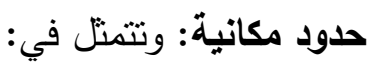

أ. في الوجه البحري: جامعة المنوفية وجامعة عين شمس ممنلة للجامعات الحكومية، جامعة ونية السادس من أكتوبر وجامعة مصر ممثلة للجـامعـات الخـاصة. ب.في الوجه القبلي: جامعة المنيا وجامعة أسيوط ممثلة للجامعات الحكومية، جامعة دراية بالمنيا وجامعة النهضة ببني سويف ممثلة للجامعات الخاصة.

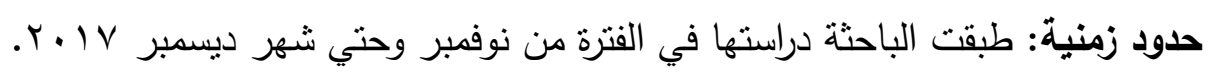

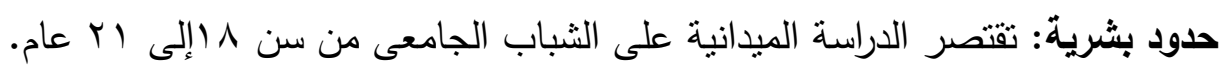

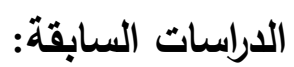

تعرض الباحثة الدراسات السابقة المرتبطة بموضوع الدراسة من خلاد الدحاور التالية: المحور الأول :دراسات تناولت الصحافة الاستقصائية التلفزيونية:

\section{توصلت دراسة Gang Han, Xiuli Wang\& Pamela shoemaker جانج}

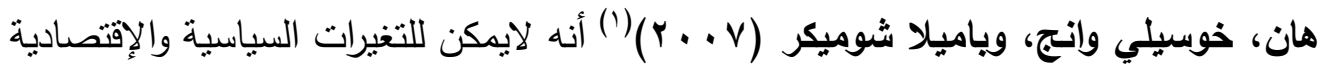

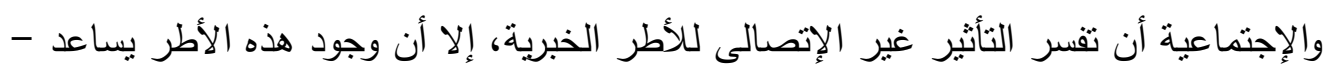

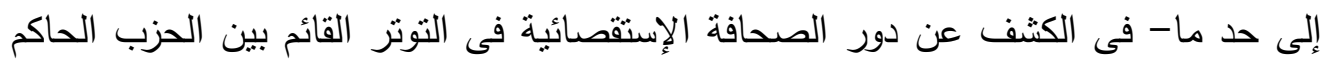

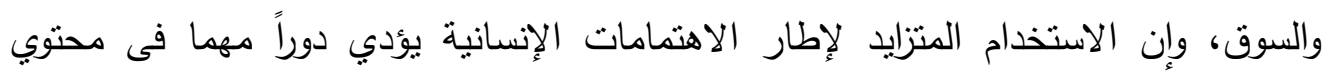

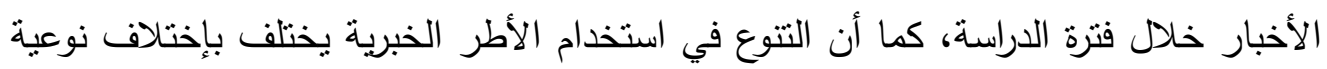

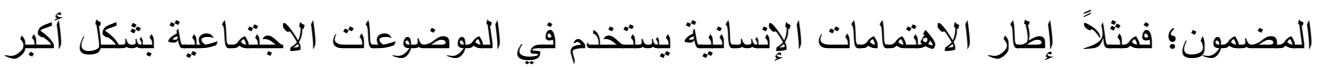

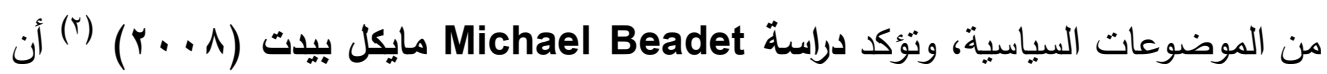
ثمانية من الصحفيين عينة الدراسة مديري المحطات فرضوا الرقابة على عدد من التقارير

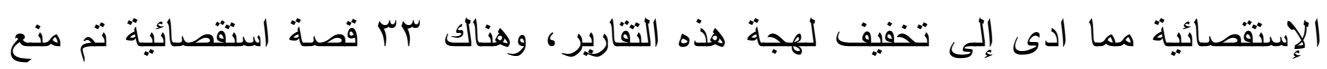
بثها على شاشة التلفزيون خلال خمس سنوات مؤكدين على أن السبب الأبرز فى منع بث

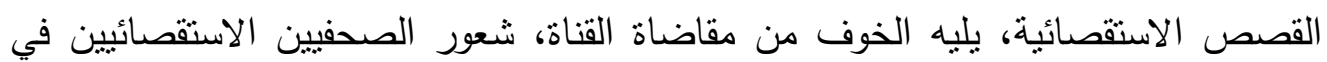

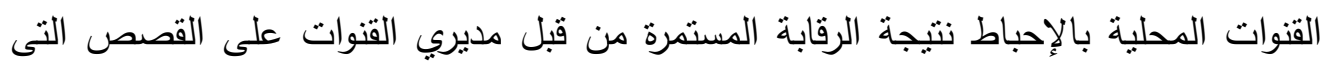
يقومون بإعدادها، وأن وراء تدخل رؤساء القنوات فى منع إذاعة التقارير الإستقصائية اعتبارات

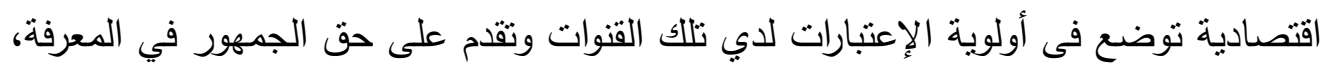

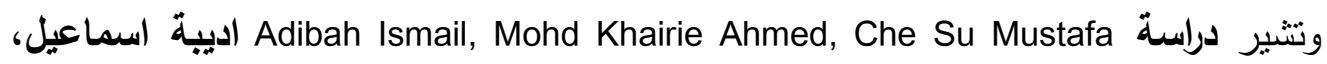




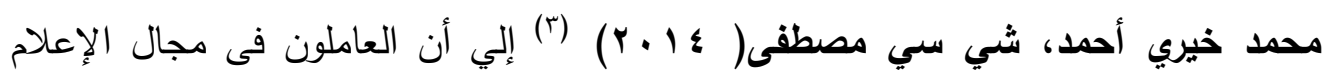

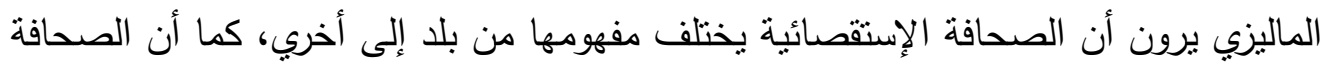

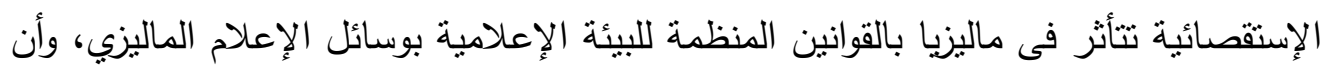
القيم والثقافة السائدة فى المجتمع من العوامل التىى تؤثر على ممارسة الصحافة الاستقصائية

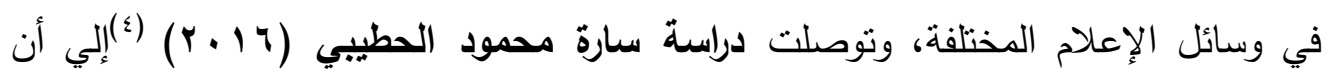
الصحفيون الاستقصائيون أجمعوا على أنه نوجد فروق بين الصحافة الاستقصائية والصحافة درائة

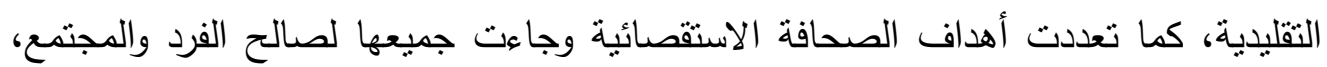

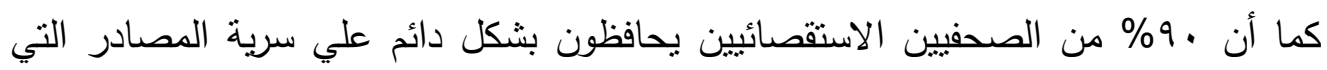
تنظلب عدم الإفصاح عنها، كما تعددت وتتوعت العقبات التي تواجه الصحفيين الاستقصائيين. المحور الثاني: دراسات تثاولت معالجة التلفزيون لقضية الإرهاب:

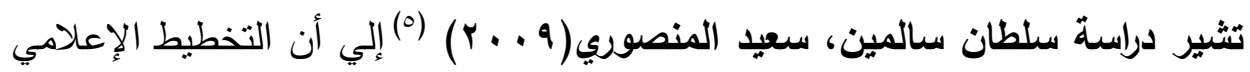

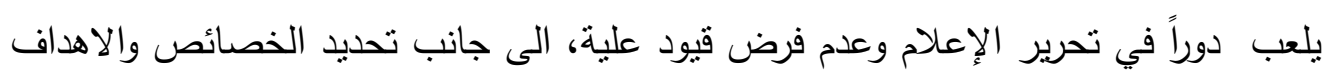

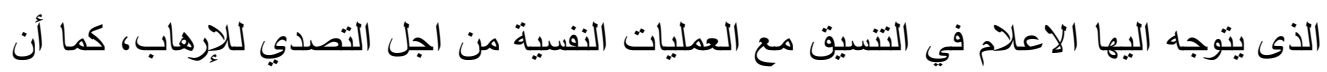
أهم وظائف التصدي لظاهرة الارهاب من خلال توسيع المشاركة الجماهيرية في اعلان آرائهم في مسائل الارهاب وكيفية التصدي لها وهو مجال يمكن من خلاله توسيع قاعدة المناهضين

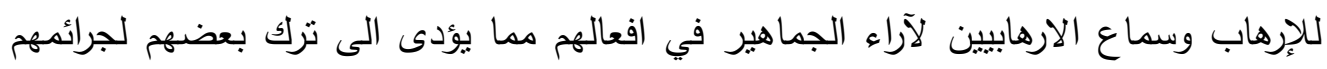
الارهابية، ويأتي التكامل الإعلامي العربي من خلال انثاء قنوات عربية موحدة " تلإيفزيون،

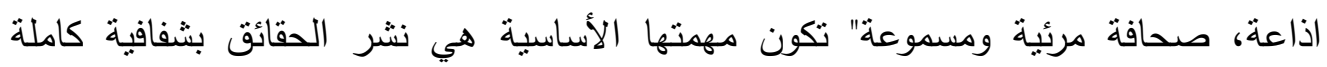
والإعلان عن الأحداث في نفس توقيت حدوثها دون تدخل من قيادات أو مراعاة نوجهات

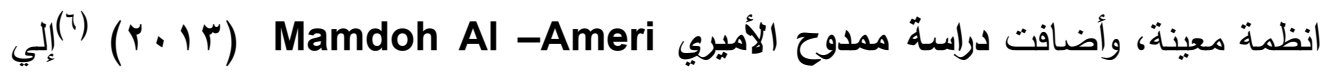
وجود علاقة طردية قوية بين التعرض لوسائل الإعلام والحصول على معلومات حول الإرهاب، وأن الطلاب عينة الدراسة موافقون على رد الحكومة علي الإرهاب ولى ومحاولة التخلص منه، وأفاد الطلاب أن الإنترنت من الأكثر المصادر الذين يعتمدون عليها للحصول ردابل

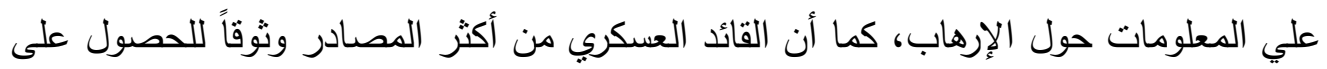

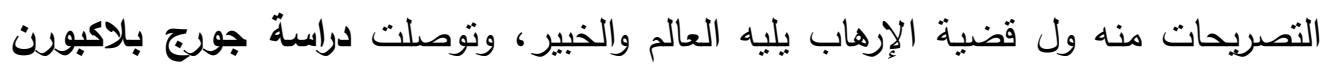

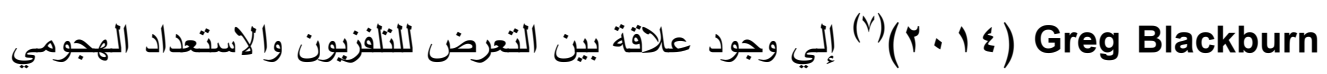


للشخص، كما أثتتت الدراسة أنه لايوجد ارتباط بين مشاهدة التلفزيون واستعداد الثخص لاتخاذ

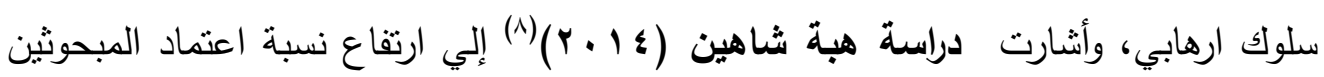
علي وسائل الإعلام المصرية للحصول علي الأخبار المتعلقة بالأحداث الإرهابية بنسبة

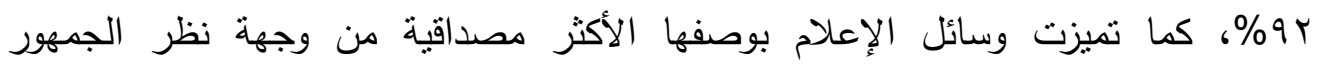
المصري، وتصدرت القنوات الفضائية المصرية الخاصة قائمة وسائل الإعلام التي يعتمد عليها بونها

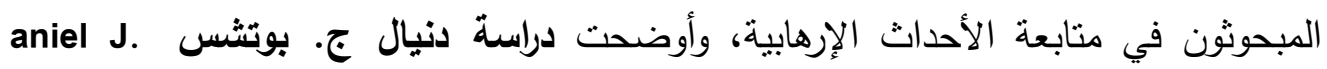
Boches

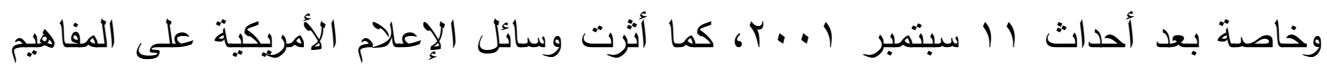

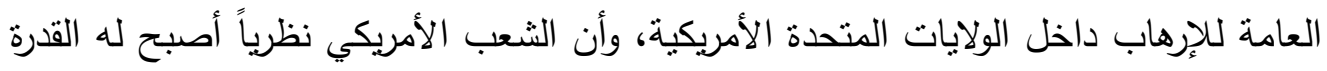
على أن يقرر السياسة العامة بما فيها السياسة الخارجية الأمريكية.

المحور الثالث: دراسات تناولت دور التلفزيون في تثكيل معارف الثباب الجامعي:

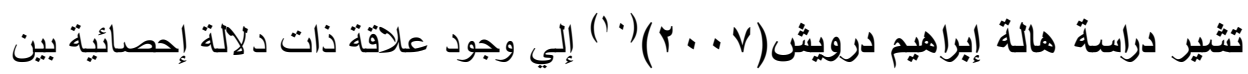
اعتماد الثباب علي البرامج الإخبارية بقناة الجزيرة كمصدر للمعلومات عن المفاهيم السياسية المختلفة والتأثثرات المعرفة والسلوكية والوجدانية لدي الثباب، أيضاً اختلاف مستوي معرفة الثباب الجامعي بالمفاهيم السياسية موضع الدراسة بإختلاف مصادر المعلومات التي يعتمدون

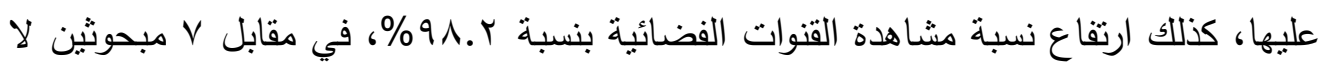

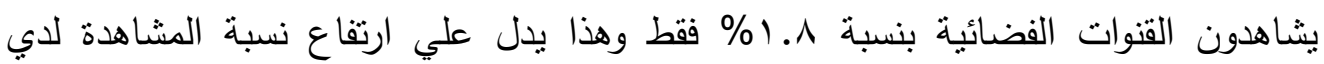

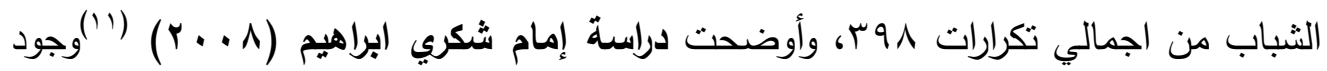

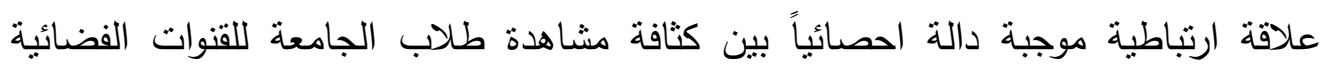

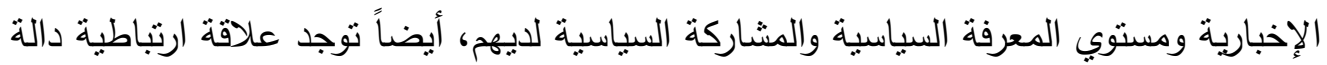

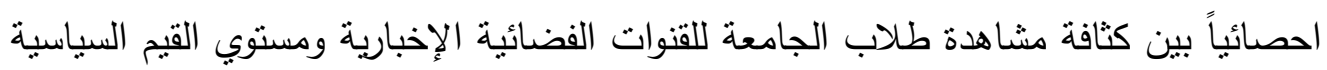

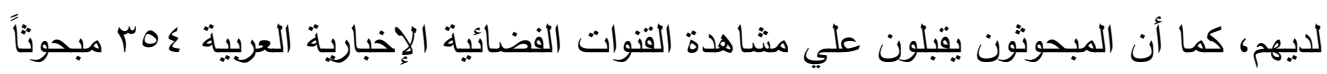

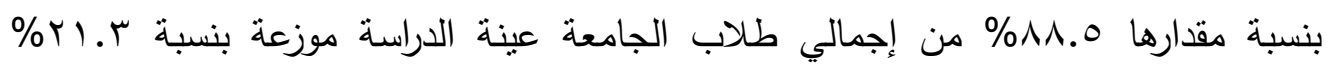

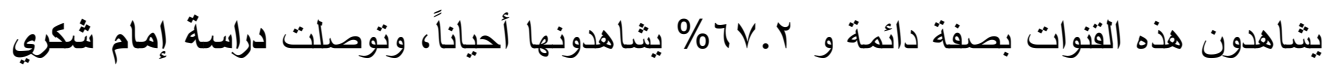

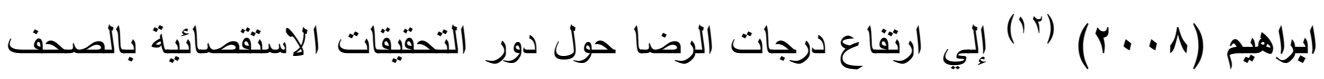
الإلكترونية في تتكيل اتجاهات الثباب الجامعي نحو قضايا الفساد، ووجود علاقة ارتباطية 
ذات دلالة احصائية بين دوافع تعرض الثباب الجامعي للتحقيقات الاستقصائية بالصحف

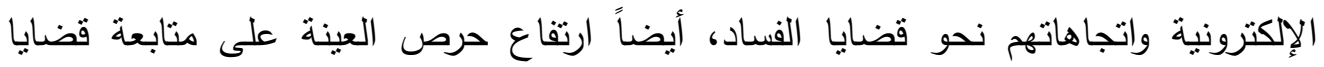

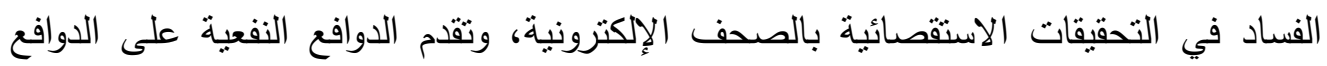
الطقوسية في أسباب تعرض عينة الدراسة من الثباب الجامعي للتحقيقات الاستقصائية

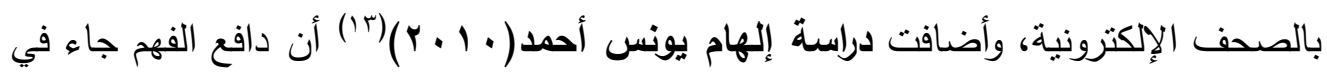

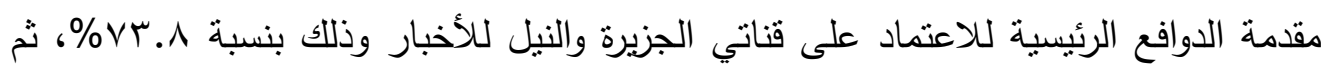

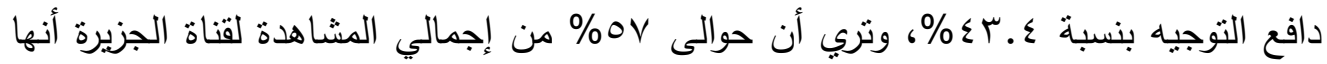

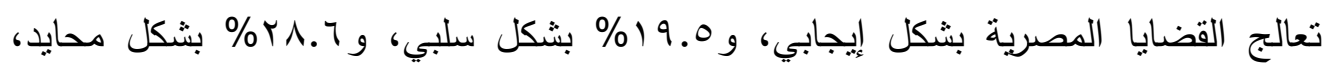

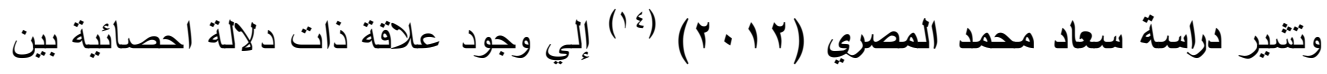

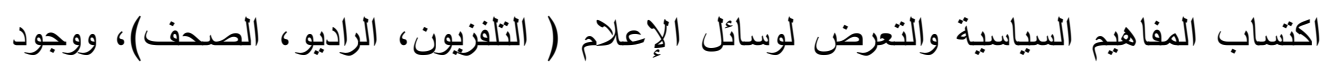

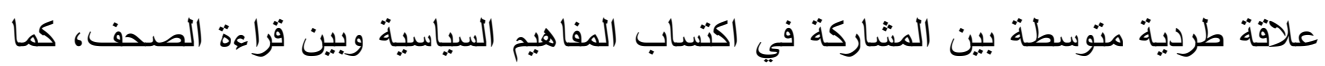

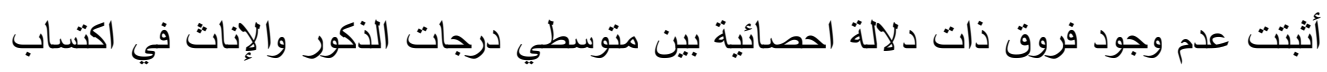
المفاهيم السياسية.

\section{نوع الدراسة ومنهجها:}

تتنمي هذه الدراسة إلي الدراسات الوصفية، وتسعي الدراسة الحالية إلي معرفة العلاقة

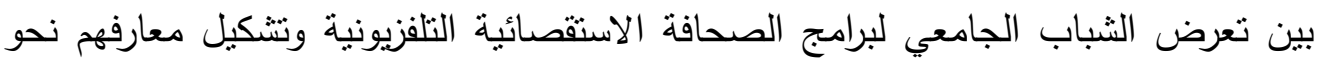

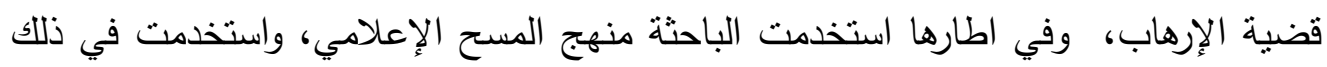
أداة الاستقصاء كأداة لجمع البيانات المطلوبة. تحديد مجتمع وعينة الدراسة: يتمثل المجتمع البشري للاراسة في الثباب الجامعي والتي تتراوح أعمارهم من سن 11 1:

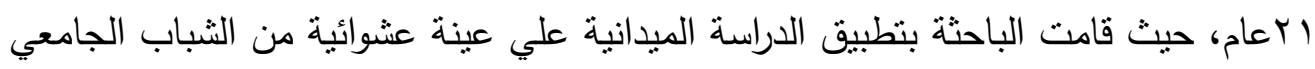

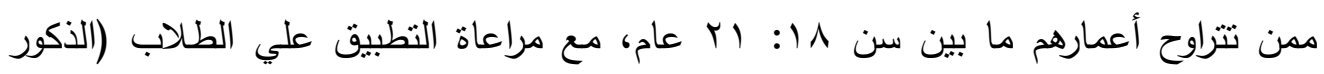

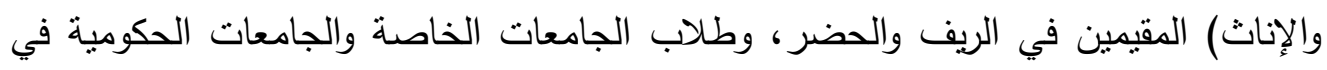

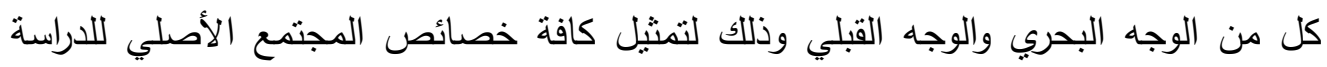
بمختلف اتجاهاتهم ولتحقيق أكبر قدر ممكن من الحيادية والموضوعية، ولتيسير عملية التعميم

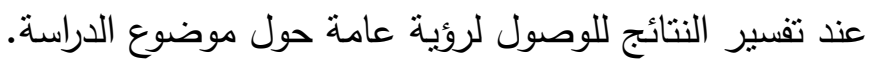


وللتأكد من صدق استمارة الاستبيان تم عرضها على مجموعة من الخبراء والمحكمين (")

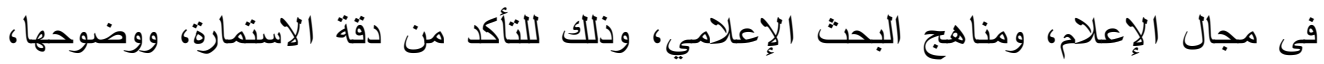

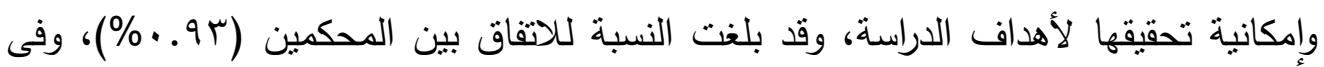

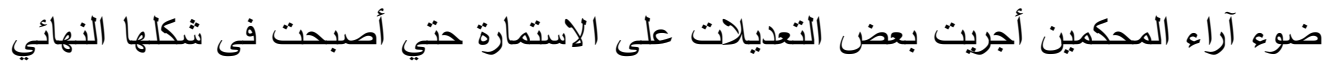
بعد (حذف بعض الفئات - إضافة بعض الفئات والبدائل).

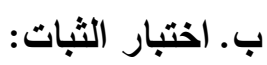

تم إجراء اختبار الثبات عن طريق إعادة تطبيق الاستمارة Retest عبرة فترة زمنية من

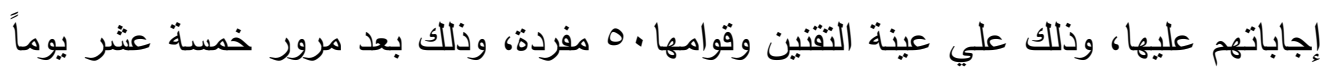
من التطبيق الأول للإستمارة، وقد اعتمدت الباحثة في حساب ثبات نتائج الإستنيان علي

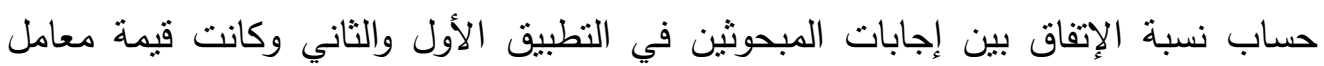
الثبات 9\%٪، وهو معامل ثبات مرتفع يدل علي عدم وجود إختلاف كبير في إجابات المبحوثين، كما يدل علي صلاحية الإستبيان للنطبيق. الأساليب المستخدمة فى تحليل البيانات:

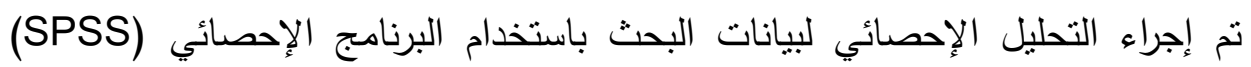

لاستخراج المعاملات وإجراء الاختبارات الإحصائية التالية:

- - مالتكرارات والنسب المئوية.

- اختبار (كروسكال واليس) كاب لدراسة معنوية الفرق بين نسبتين مئويتين.

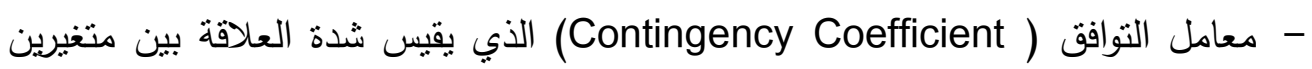

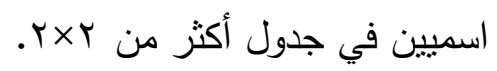
- اختبار "Z .Test " لدراسة معنوية الفرق بين نسبتين مئويتين.

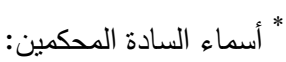

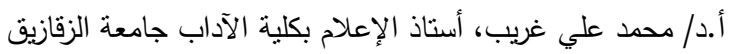

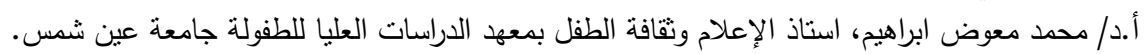

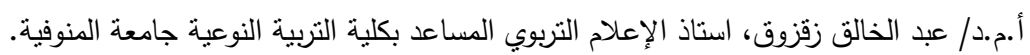

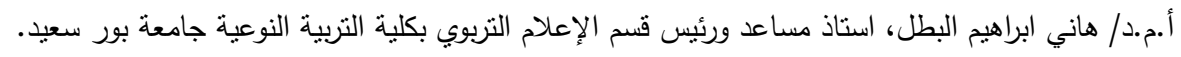
د. بسنت عبد المحسن العقباوي، ددرس الإعلام التربوي بكلية التربية النوعية جامعة المنوفية. 


\section{نتائج الدراسة:}

\section{مدي مشاهدة افراد العينة لبرامج الصحافة الاستقصائية التليفزيونية.}

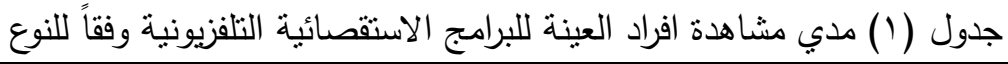

\begin{tabular}{|c|c|c|c|c|c|c|}
\hline \multicolumn{2}{|c|}{ الإجمالي } & \multicolumn{2}{|c|}{ أناث } & \multicolumn{2}{|c|}{ ذكور } & \multirow[b]{2}{*}{ مدي المشاهدة } \\
\hline$\%$ & ك & $\%$ & ك & $\%$ & ك & \\
\hline 11 & $\leqslant \varepsilon$ & Ir.r & $Y \varepsilon$ & 1. & $r$. & دائما \\
\hline$\leq 0$ & $1 \wedge$. & $\leqslant 7.0$ & q & $\leqslant \Gamma .0$ & NV & أحياناً \\
\hline$\varepsilon \varepsilon$ & 187 & $\leqslant 1.0$ & Nז & $\leqslant 7.0$ & $9 \pi$ & $\gamma$ \\
\hline $1 \ldots$ & $\varepsilon \ldots$ & $1 \ldots$ & $r \ldots$ & $1 \ldots$ & r.. & المجموع \\
\hline
\end{tabular}

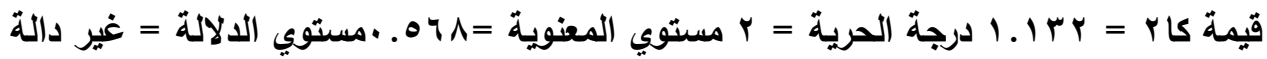
تدل بيانات الجدول السابق علي نسبة من يشاهدون برامج الصحافة الاستقصائية

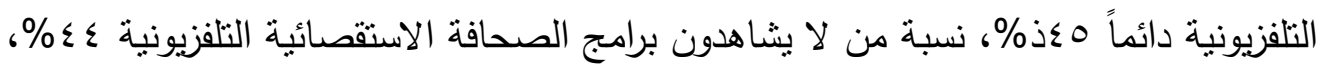

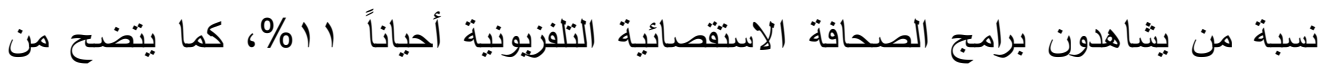

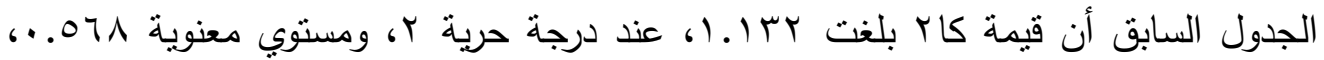

$$
\text { وهي قيمة غير دالة إحصائياً. }
$$

الأماكن التي يثاهد فيها افراد العينة برامج الصحافة الاستقصائية التلفزيونية.

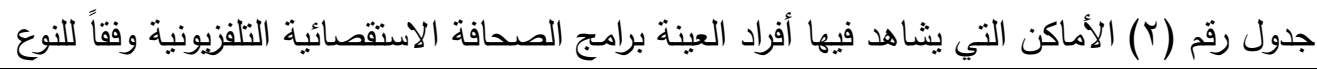

\begin{tabular}{|c|c|c|c|c|c|c|c|c|c|}
\hline \multirow[t]{2}{*}{ التزتيب } & \multirow[t]{2}{*}{ الدلالة } & \multirow[t]{2}{*}{ قيمة Z } & \multicolumn{2}{|c|}{ الإجمالي } & \multicolumn{2}{|l|}{ أناث } & \multicolumn{2}{|l|}{ ذكور } & \multirow{2}{*}{ القنوات } \\
\hline & & & $\%$ & ك & $\%$ & ك & $\%$ & ك & \\
\hline r & غبر داله &..$r q$. & $r 9.9$ & TV & rq. & $r \varepsilon$ & $r \cdot . \Lambda$ & זr & بالتليفزيون القنوات الفضائية \\
\hline$r$ & غير داله &. .170 & TV.V & 74 & TV.E & rt & rᄉ & $r$. & للقنى الموات التلفزيونية الإخبارية \\
\hline 1 & غير داله & r & T.T & $v \cdot$ & $r \cdot . \Lambda$ & 4 & r.. & $r \varepsilon$ & الاجتماعي مواقع التواصل \\
\hline$\varepsilon$ & غير داله & . r r & $1 v .9$ & $\varepsilon$. & 11.1 & rr & 17.1 & 11 & جميع ما سبق \\
\hline & & & *Yrs & & $11 \mathrm{~V}$ & & $1 \cdot v$ & & جملة من سئلوا \\
\hline
\end{tabular}


تشير بيانات الجدول السابق إلي الأماكن التي يشاهد فيها أفراد العينة برامج الصحافة

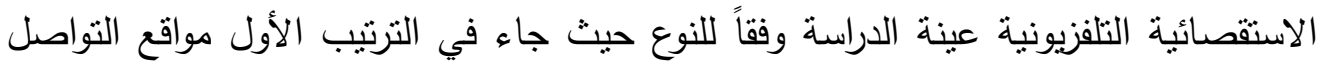

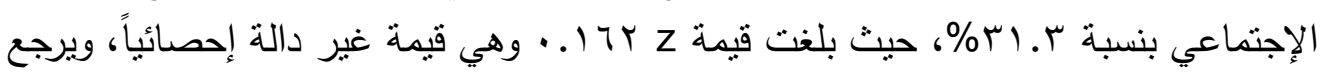

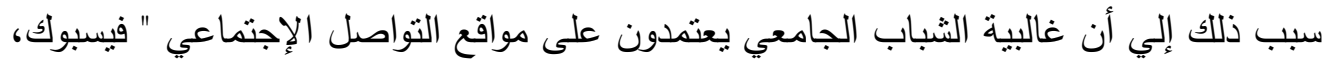

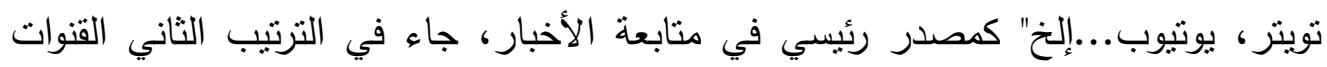

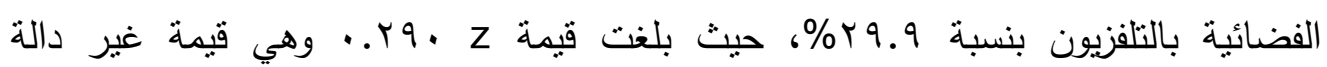

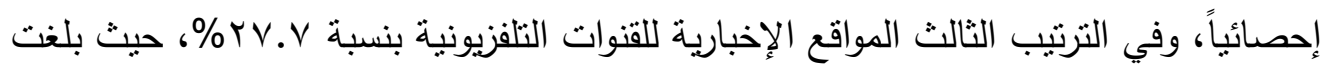

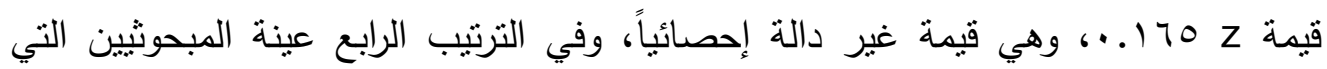

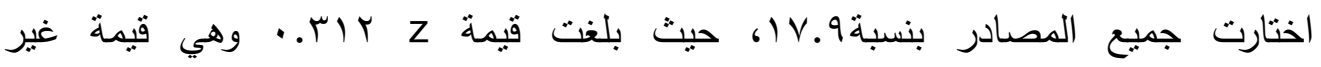
دالة إحصائياً.

معدل مشاهدة أفراد العينة لبرامج الصحافة الاستقصائية التليفزيونية.

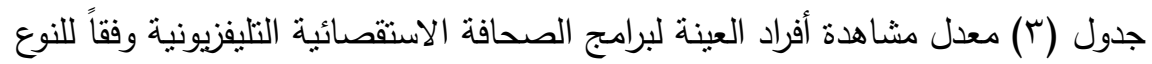

\begin{tabular}{|c|c|c|c|c|c|c|}
\hline \multicolumn{2}{|c|}{ الإجمالي } & \multicolumn{2}{|l|}{ أناث } & \multicolumn{2}{|l|}{ ذكور } & \multirow[t]{2}{*}{ العينة } \\
\hline$\%$ & ك5 & $\%$ & ك5 & $\%$ & ك5 & \\
\hline 17.1 & ד & $10 . \varepsilon$ & 11 & 17.1 & 11 & دائما \\
\hline צ.rT & $1 \leqslant r$ & Tr.T & $V \varepsilon$ & ד.זד & 71 & أحياناً \\
\hline$r . .0$ & $\sum 7$ & Y. & ro & rI & rI & $\gamma$ \\
\hline $1 \ldots$ & TYS & $1 \ldots$ & $11 \mathrm{~V}$ & $1 \ldots$ & $1 . v$ & المجموع \\
\hline
\end{tabular}

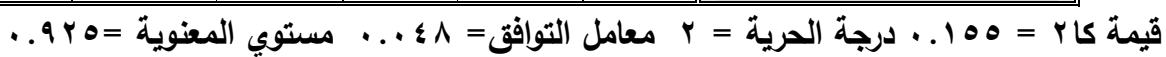
مستوي الدلالة = غير دالة

تدل بيانات الجدول السابق علي أن أغلب المبحوثين عينة الدراسة يشاهدون برامج

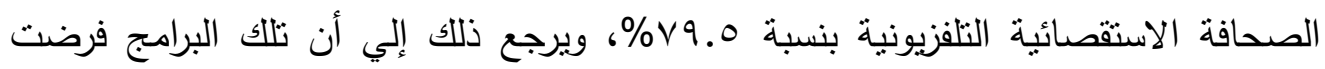
نفسها علي الساحة الإعلامية من خلال كثفها لكل مايتم اخفاؤه علي الجمهور ، والبحث دائمة دائماً

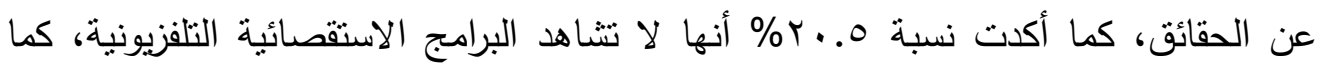

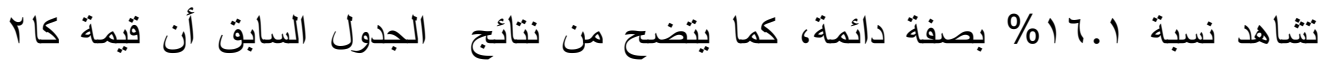

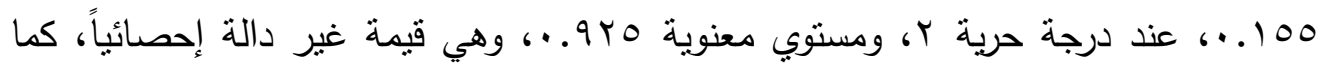

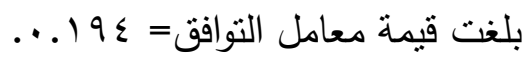


أهم برامج الصحافة الاستقصائية التلفزيونية التي يفضل المبحوثين مابعتها وفقاً:

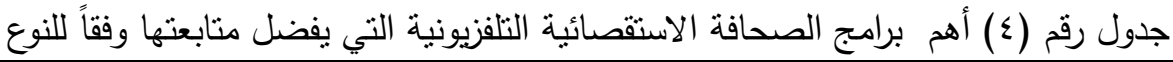

\begin{tabular}{|c|c|c|c|c|c|c|c|}
\hline \multirow[t]{2}{*}{ 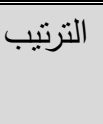 } & \multicolumn{2}{|c|}{ الإجمالي } & \multicolumn{2}{|l|}{ أناث } & \multicolumn{2}{|l|}{ ذكور } & \multirow{2}{*}{ القنوات } \\
\hline & $\%$ & ك & $\%$ & 5) & $\%$ & ك) & \\
\hline 1 & rq.V & 19 & r.^ & $\varepsilon r$ & $\varepsilon r$ & $\leqslant 7$ & برنامج انتباه للإعلامية مني عراقي \\
\hline r & rq.9 & $7 V$ & rq. & $r \varepsilon$ & $r \cdot . \Lambda$ & 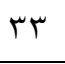 & برنامج سري للغاية للإعلامي يسري فودة \\
\hline$\varepsilon$ & $1 \% . \Lambda$ & 少 & 10.5 & 11 & 14.1 & it & برنامج نقطة ساخنة للإعلامي أسعد طه \\
\hline \multirow[t]{2}{*}{ r } & Y.. & $\varepsilon \wedge$ & $r \varepsilon . \wedge$ & rq & $1 V .1$ & 19 & كل ذلك \\
\hline & \multicolumn{2}{|l|}{ *YY } & \multicolumn{2}{|l|}{$11 \mathrm{~V}$} & \multicolumn{2}{|l|}{$1 \cdot v$} & جملة من سئلوا \\
\hline
\end{tabular}

تدل بيانات الجدول السابق علي: أن برنامج انتباه من أكبر البرامج مشاهدةً لعينة الدراسة

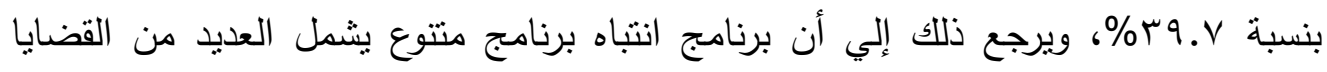
الإجتماعية والسياسية والإقتصادية والصحية وهو مايجذب الثنباب الجامعي لمشاهدتة، أيضاً هو برنامج يبث بشكل منتظم وليس برنامج متوقف كباقي البرامج المتاحة في الإختيارات، جاء

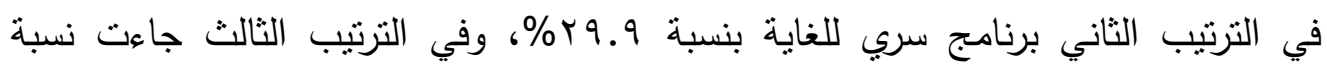

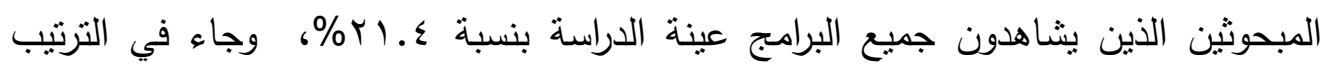

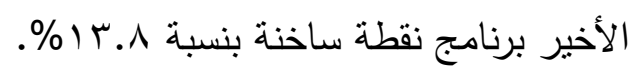

دوافع مشاهدة المبحوثين للبرامج الاستقصائية التلفزيونية عينة الدراسة وفقاً للنوع: جدول رقم (0) دوافع مشاهدة المبحوثين لبرامج الصحافة الاستقصائية التلفزيونية وفقاً للنوع لإنئه

\begin{tabular}{|c|c|c|c|c|c|c|c|}
\hline \multirow[t]{2}{*}{ الترتيب } & \multicolumn{2}{|c|}{ 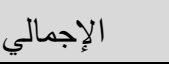 } & \multicolumn{2}{|l|}{ أناث } & \multicolumn{2}{|l|}{ ذكور } & \multirow{2}{*}{ عدد البرامج } \\
\hline & $\%$ & 5) & $\%$ & ك5 & $\%$ & ك & \\
\hline 1 & rq.r & $\wedge \wedge$ & $\varepsilon \cdot . r$ & $\leqslant V$ & ґА. & $\varepsilon 1$ & 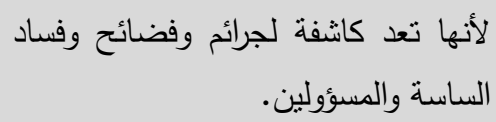 \\
\hline 1 & rq.r & $\wedge \wedge$ & r..人 & $\varepsilon r$ & $\leq Y .1$ & $\leqslant 0$ & تالاجتمق فهية لمعرفة الأحداث السباسية والاقتصادية \\
\hline r & T.T & $v r$ & r l & $r q$ & r.. & r纟 & لأنها تزودني بوجهات نظر مختلفة. \\
\hline 9 & $10 . r$ & re & $1 T . V$ & 17 & 17.1 & 11 & شكل جديد من البرامج التلفزيونية. \\
\hline$\checkmark$ & 19.4 & $\varepsilon r$ & Y.. & ro & 17.1 & 11 & ارتفاع درجة مصداقيتها. \\
\hline
\end{tabular}

*سؤال متعدد الإجابات وليس على عينة الدراسة فقط. 


\begin{tabular}{|c|c|c|c|c|c|c|c|}
\hline \multirow[t]{2}{*}{ 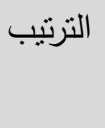 } & \multicolumn{2}{|c|}{ الإجمالي } & \multicolumn{2}{|l|}{ أناث } & \multicolumn{2}{|l|}{ 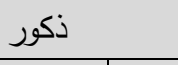 } & \multirow{2}{*}{ عدد البرامج } \\
\hline & $\%$ & 5 & $\%$ & 5) & $\%$ & 5) & \\
\hline r & TV.r & 71 & $r \varepsilon . \Lambda$ & rq & rq.9 & rt & الجرأة في تتاول الموضوع. \\
\hline 9 & $10 . r$ & rะ & IT.V & 17 & 17.1 & 11 & الانفراد بالمعلومات والحقائق. \\
\hline 1. & 14.0 & rA & Ir.A & 10 & $\mid r .1$ & Ir & التوازن والموضوعية في التناول. \\
\hline 0 & YI. & $\varepsilon \wedge$ & $1 V .1$ & $r \cdot$ & Y५. & $r \wedge$ & الأصاة للوصول إلى الحقيقة" من مصدرها \\
\hline 7 & $r \cdot . l$ & $\leq 0$ & Y.. & ro & TY.S & $r \varepsilon$ & للمشاهدة. \\
\hline 7 & $r \cdot . l$ & $\leq 0$ & $1 \wedge . \wedge$ & rt & r).0 & r & تحلل الظواهر والأحداث المختلفة. \\
\hline$\varepsilon$ & rT.V & or & Tr. & $r \uparrow$ & YO. Y & rV & تقدم لي تفسيراً للأحداث الدولية والمحلية \\
\hline$\wedge$ & $1 \wedge .1$ & $\varepsilon r$ & 17.4 & 19 & YI.0 & r & لها دور في تشكيل معارفي تجاه القضايا \\
\hline 7 & $r \cdot . l$ & $\leq 0$ & Y.. & ro & $1 \wedge . \vee$ & $r \cdot$ & تلعب دوراً في توضيح مفهوم الإرهاب \\
\hline \multirow[t]{2}{*}{11} & 11.7 & r & ir & $1 \varepsilon$ & $11 . r$ & ir & تقبدني في مجال عملي \\
\hline & \multicolumn{2}{|l|}{ *Yrs } & \multicolumn{2}{|l|}{$11 \mathrm{~V}$} & \multicolumn{2}{|l|}{$1 \cdot v$} & جملة من سئلوا \\
\hline
\end{tabular}

تشير بيانات الجدول السابق إلي أن أهم دوافع مشاهدة المبحوثين للبرامج الاستقصائية

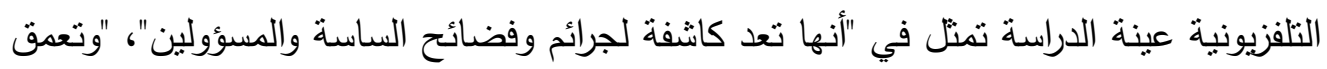

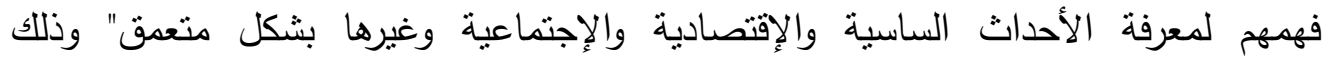

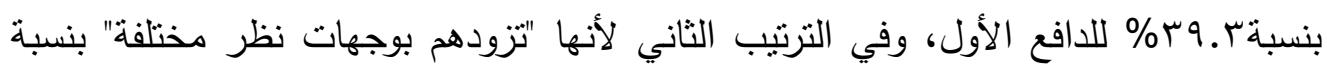

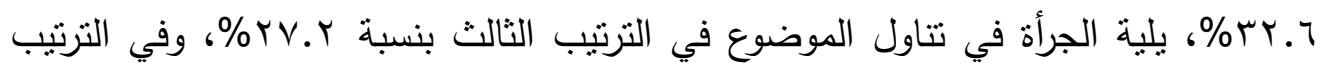

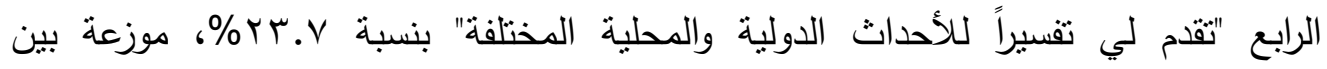

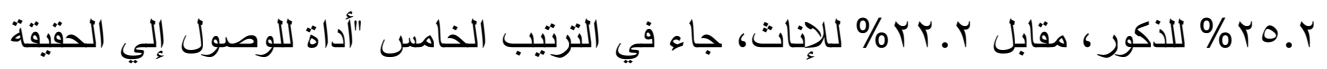

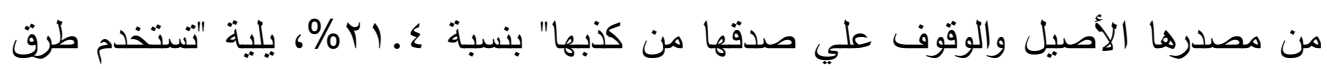


أكثر جاذبية للمشاهدة"، "تحلل الظواهر والأحداث المختلفة" في الترتيب السادس بنسبة

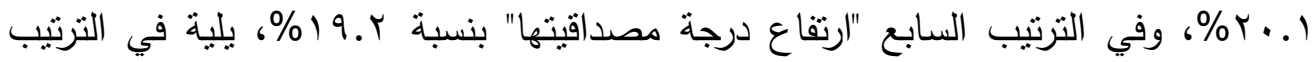

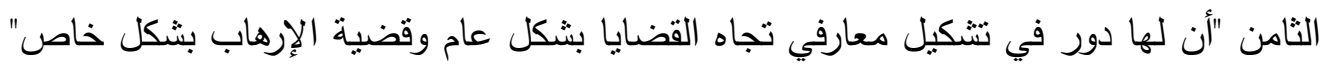

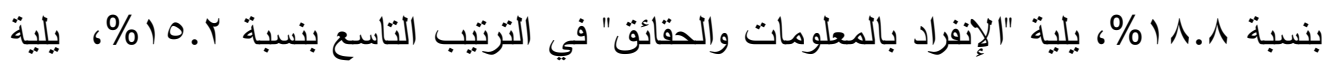

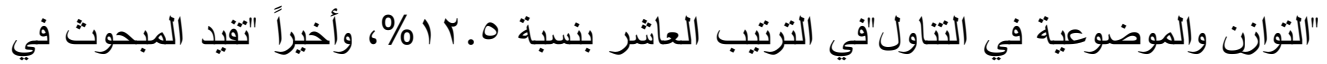
مجال عمله" بنسبة 7 . 1 ( \% من عينة مشاهدى البرامج الاستقصائية التلفزيونية. معدل متابعة أفراد العينة لقضايا الإرهاب ببرامج الصحافة الاستقصائية التلفزيونية. جدول (7) معدل متابعة أفراد العينة لقضايا الإرهاب ببرامج الصحافة الاستقصائية التلفزيونية وفقاً للنوع

\begin{tabular}{|c|c|c|c|c|c|c|}
\hline \multicolumn{2}{|c|}{ الإجمالي } & \multicolumn{2}{|c|}{ أناث } & \multicolumn{2}{|c|}{ ذكور } & \\
\hline$\%$ & ك5 & $\%$ & ك5 & $\%$ & 5 & مـ \\
\hline$r \leq .1$ & $0 \leqslant$ & rT.q & $11 \mathrm{~V}$ & $r \leq . r$ & rT & دائما \\
\hline or.t & ir. & or. 1 & 71 & 00.1 & 09 & أحياناً \\
\hline YT.T & 0. & rr.q & rA & $r \cdot . T$ & rY & نادراً \\
\hline $1 \ldots$ & YYS & $1 \ldots$ & $11 \mathrm{~V}$ & $1 \ldots$ & $1 . V$ & المجموع \\
\hline
\end{tabular}

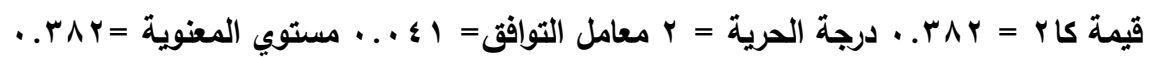

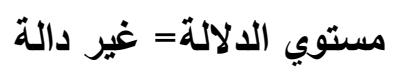

تدل بيانات الجدول السابق علي معدل متابعة أفراد العينة لقضايا الإرهاب بيرامج

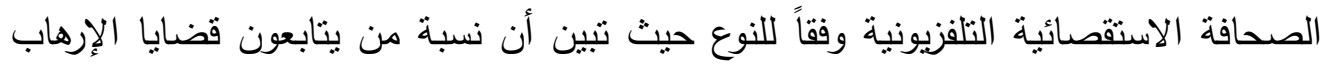

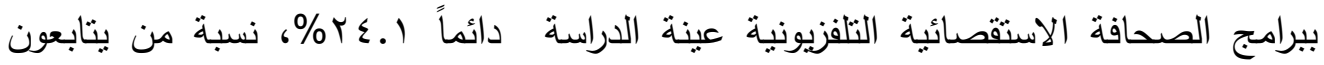

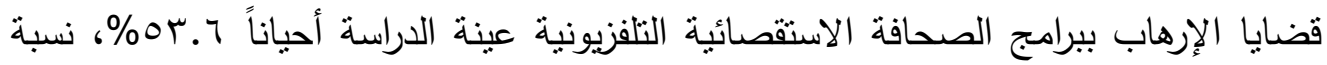
من يتابعون قضايا الإرهاب ببرامج الصحافة الاستقصائية التلفزيونية عينة الدراسة نادراً

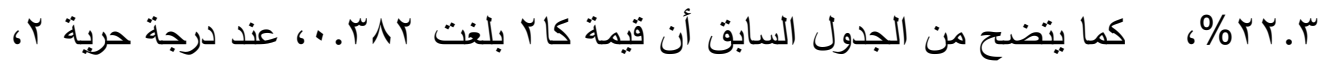

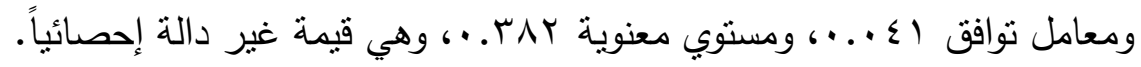

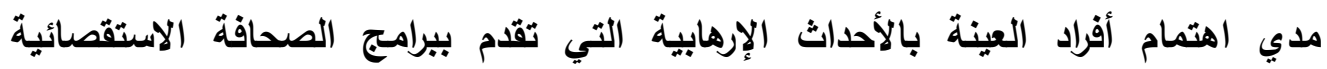

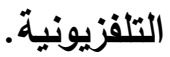


جدول (V) مدي اهتمام أفراد العينة بالأحداث الإرهابية التي تقام ببرامج الصحافة

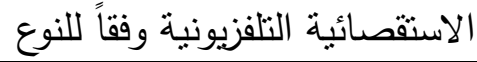

\begin{tabular}{|c|c|c|c|c|c|c|}
\hline \multicolumn{2}{|c|}{ الإجمالي } & \multicolumn{2}{|c|}{ أناث } & \multicolumn{2}{|c|}{ ذكور } & العينة \\
\hline$\%$ & ك5 & $\%$ & ك5 & $\%$ & s & \\
\hline$r V . r$ & 71 & YA.Y & זr & rצ. & rA & دائما \\
\hline$\{0.0$ & $1 . r$ & $\varepsilon 1$ & $\leqslant \wedge$ & 0.0 & $0 \leqslant$ & أحياناً \\
\hline$r V . r$ & 71 & $r . . \Lambda$ & ז & Tr.s & ro & نادراً \\
\hline $1 \ldots$ & TYS & $1 \ldots$ & $11 \mathrm{~V}$ & $1 \ldots$ & $1 . v$ & المجموع \\
\hline
\end{tabular}

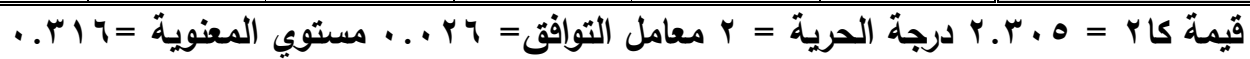

$$
\text { مستوي الدلالة = غير دالة }
$$

تدل بيانات الجدول السابق علي مدي اهتمام أفراد العينة بالأحداث الإلة الإهابية التي تقدم

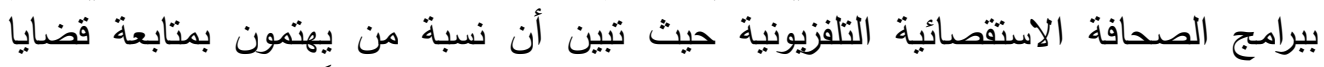

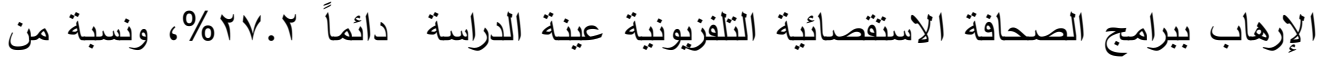

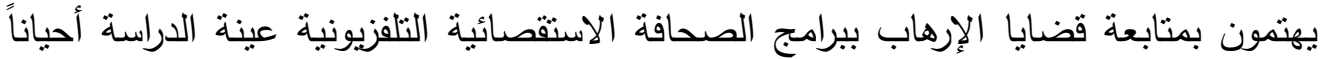

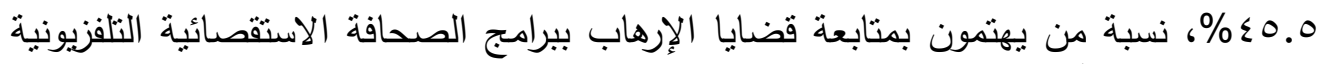

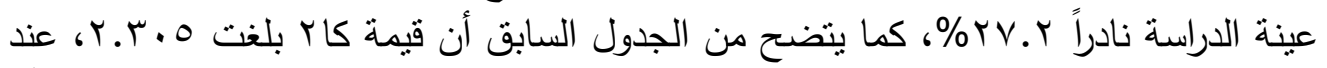

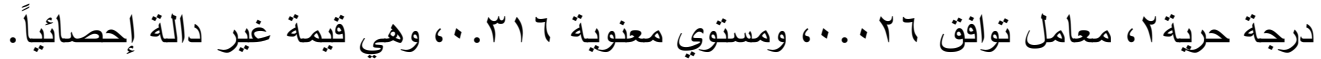

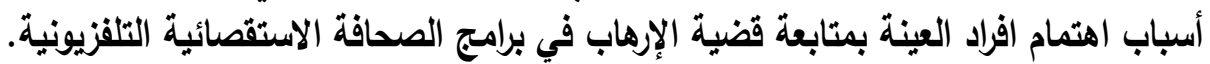

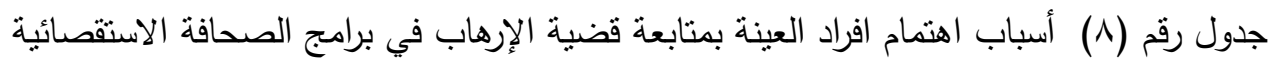
التلفزيونية وفقاً للنوع

\begin{tabular}{|c|c|c|c|c|c|c|c|c|c|}
\hline \multirow[t]{2}{*}{ التزتيب } & \multirow[t]{2}{*}{ الدلالة } & \multirow[t]{2}{*}{ قيمة z } & \multicolumn{2}{|c|}{ الإجمالي } & \multicolumn{2}{|l|}{ أناث } & \multicolumn{2}{|l|}{ ذكور } & \multirow[b]{2}{*}{ الاسباب } \\
\hline & & & $\%$ & ك & $\%$ & ك & $\%$ & ك & \\
\hline r & غير & $\cdot . \wedge .1$ & r..A & 7. & rq. & $\Gamma \varepsilon$ & $r \leq . r$ & TY & العزبية أعيش فيه وفى الإرهاب في المجتمق \\
\hline 1 & داله & $. r \leqslant 1$ & TV.O & $\wedge \varepsilon$ & r.. & $\varepsilon r$ & rA.r & $\leqslant 1$ & لالمجنمية قالدية الإرهاب بالنسبة \\
\hline$r$ & داله & 1.199 & ro. 9 & 01 & $r \leq . \Lambda$ & rq & YV. & rq & تضية الإرهاب من معلوماتي حول \\
\hline
\end{tabular}




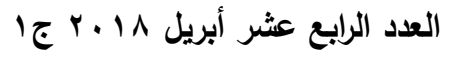

\section{المجلة العلمية لكلية التربية النوعية}

\begin{tabular}{|c|c|c|c|c|c|c|c|c|c|}
\hline \multirow[t]{2}{*}{ الترتيب } & \multirow[t]{2}{*}{ الدلالة الد } & \multirow[t]{2}{*}{ قيمة z } & \multicolumn{2}{|c|}{ الإجمالي } & \multicolumn{2}{|l|}{ أناث } & \multicolumn{2}{|l|}{ ذكور } & \multirow[b]{2}{*}{ الاسباب } \\
\hline & & & $\%$ & ك5 & $\%$ & ك & $\%$ & ك & \\
\hline 0 & 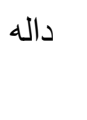 & . & $1 V .9$ & $\varepsilon$. & $1 Y .9$ & r) & IV.A & 19 & تشكاعدني في تشكيل معارفي \\
\hline 7 & 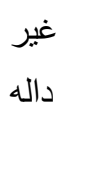 & $\ldots r V$ & $10 . \mathrm{r}$ & $r \varepsilon$ & 17.5 & 19 & $1 \varepsilon$ & 10 & 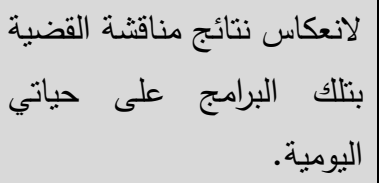 \\
\hline 7 & غاله & .. $\{71$ & $10 . r$ & rs & 17.5 & 19 & $1 \varepsilon$ & 10 & تتتاسب مع اهتماماتي. \\
\hline$\varepsilon$ & غاله &.$\Gamma \wedge 0$ & ro & 07 & rT. & rV & rY.I & rq & 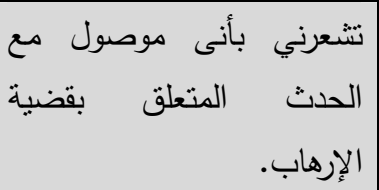 \\
\hline & & & RYY & & $11 \mathrm{~V}$ & & $1 . V$ & & جملة من سئلوا \\
\hline
\end{tabular}

نلاحظ من نتائج الجدول السابق أن هناك اختلاف بين أسباب الإهتمام المبحوثين

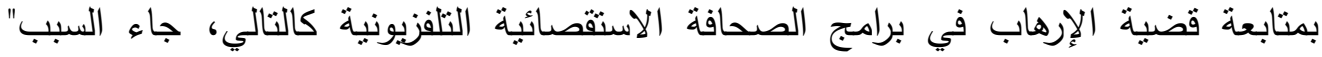
لأهمية قضية الإرهاب بالنسبة للمجتمع المصري والعربي والدية والدولي" في مقدمة الأسباب بنسبة

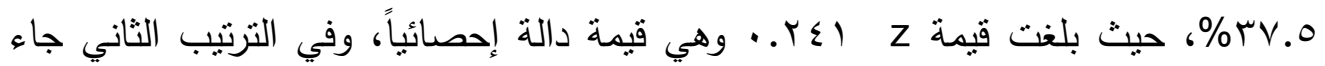

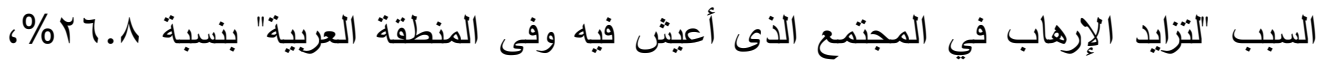

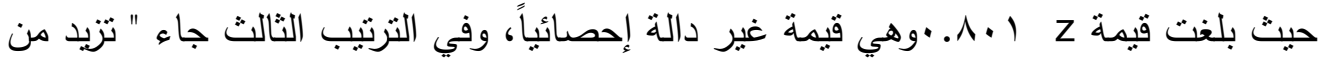

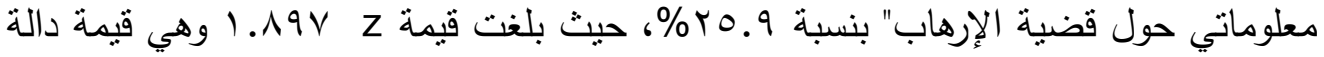

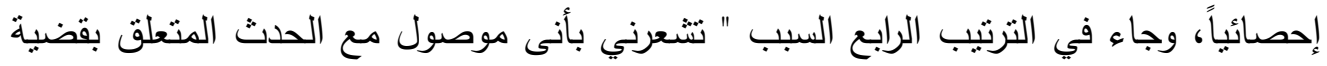

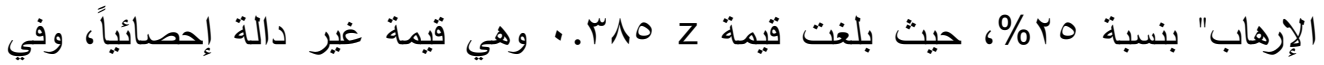

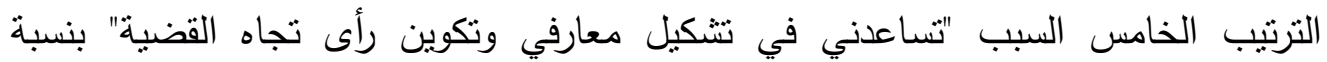

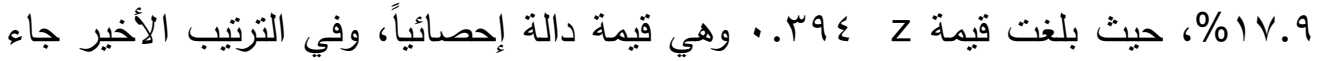

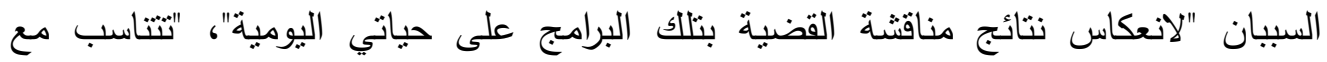

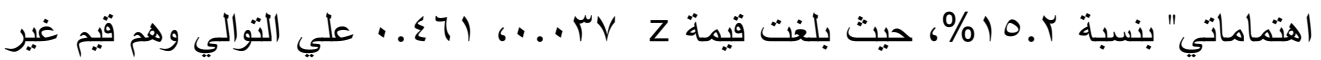
دالة إحصائياً. 
صور الإرهاب كما تناولها برامج الصحافة الاستقصائية التلفزيونية من خلال متابعة أفراد العينة لتغطية برامج الصحافة الاستقصائية التلفزيونية لقضية الإرهاب.

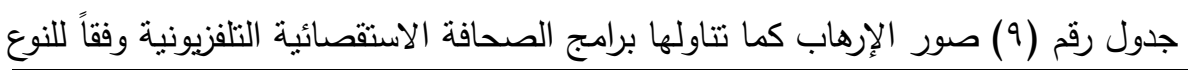

\begin{tabular}{|c|c|c|c|c|c|c|c|c|c|}
\hline \multirow[t]{2}{*}{ التزتيب } & \multirow[t]{2}{*}{ الدلالة } & \multirow[t]{2}{*}{ ق قيمةة } & \multicolumn{2}{|c|}{ الإجمالي } & \multicolumn{2}{|l|}{ أناث } & \multicolumn{2}{|l|}{ ذكور } & \multirow{2}{*}{ الصور } \\
\hline & & & $\%$ & ك & $\%$ & s] & $\%$ & 5 & \\
\hline 0 & غير داله & $\cdots 7$ & 19.7 & $\varepsilon \varepsilon$ & 19.8 & rt & 19.7 & r) & اختطاف الطائرات والسفن \\
\hline 1 & غير داله & $\ldots v r$ & ro.r & $\mathrm{vq}$ & ro & \&) & ro.0 & rᄉ & التفجيرات الإرهابية \\
\hline r & غير داله &..$r 9 \varepsilon$ & $r \leqslant .7$ & 00 & ro.t & r. & rT.\& & ro & احتجاز الرهائن \\
\hline 7 & غير داله & .01 .9 & $1 \leq . \Gamma$ & r & $1 \leq .0$ & iv & $1 \varepsilon$ & 10 & الأسلحة البيولوجية \\
\hline r & غير داله &. $.1 Y 4$ & rA. & $T \varepsilon$ & YA. r & זי & rq & r & الاغنيالات السياسية \\
\hline$\varepsilon$ & 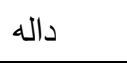 & T.IAT & $r . .1$ & «o & ro & $r$. & $1 \varepsilon$ & 10 & الإرهاب النووي \\
\hline V & غير داله &. .701 & 11.7 & rt & $1 . .5$ & Ir & 14.1 & $1 \leq$ & كل ذللك \\
\hline & & & *YY & & $11 \mathrm{~V}$ & & $1 . v$ & & Wh \\
\hline
\end{tabular}

نلاحظ من نتائج الجدول السابق تعدد صور الإرهاب التي تتاولتها برامج الصائه الصحافة

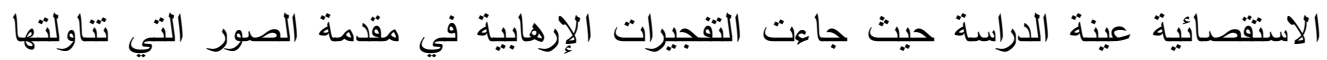

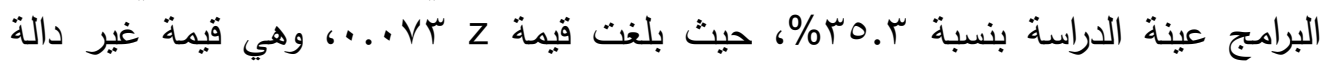

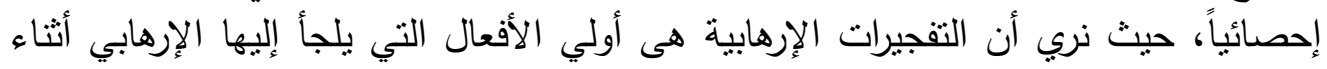

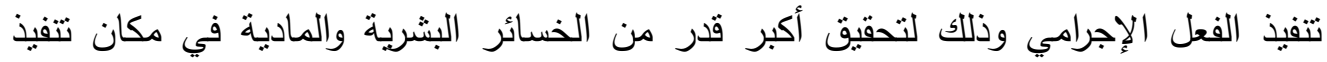

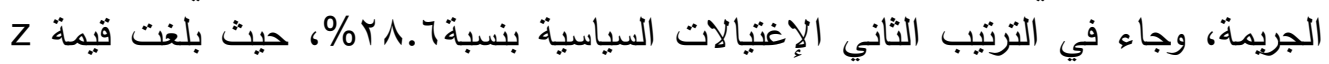

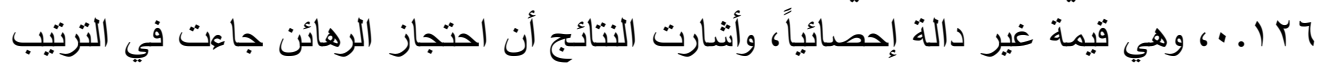

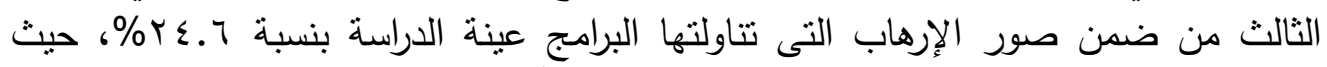

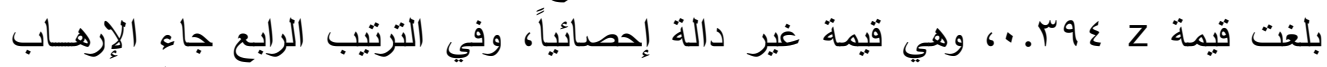

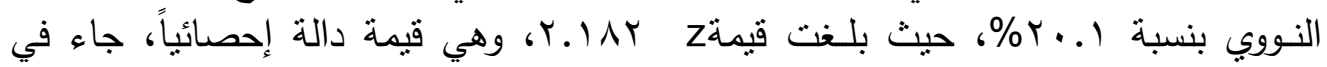

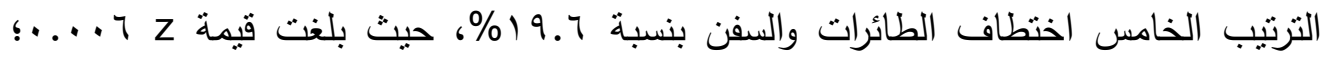

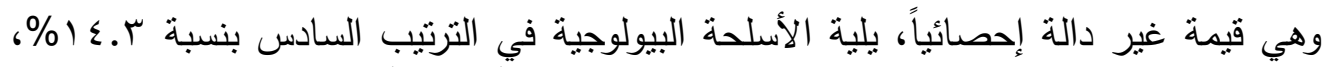

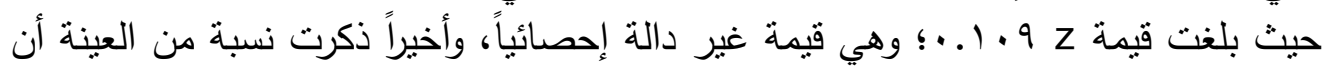

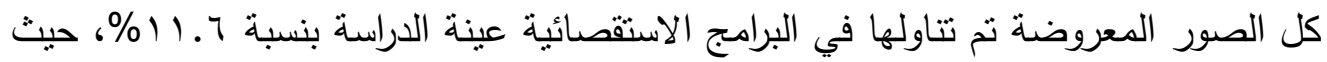

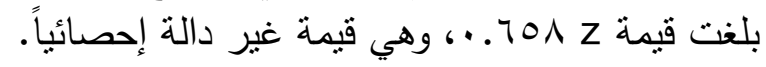


مدي مساهمة برامج الصحافة الاستقصائية التلفزيونية في تثكيل معارف افراد العينة نحو قضية الإرهاب جدول (· ( ) مدي مساهمة برامج الصحافة الاستقصائية التلفزيونية في تنكيل معارف افراد العينة نحو قضية الإرهاب وفقاً للنوع

\begin{tabular}{|c|c|c|c|c|c|c|}
\hline \multicolumn{2}{|c|}{ الإجمالي } & \multicolumn{2}{|l|}{ أناث } & \multicolumn{2}{|l|}{ ذكور } & \multirow[t]{2}{*}{ النوع } \\
\hline$\%$ & ك5 & $\%$ & كs & $\%$ & ك5 & \\
\hline $1 \leq . V$ & Tr & 11.1 & ir & IA.V & $r$. & تساهم \\
\hline Vo.9 & iv. & $\vee 9.0$ & वा & VY & VV & تساهم إلي حد ما \\
\hline $9 . \varepsilon$ & r) & $V . \varepsilon$ & 11 & $9 . r$ & 1. & نادراً ماتساهم \\
\hline $1 \ldots$ & TYE & $1 \ldots$ & $11 \mathrm{~V}$ & $1 \ldots$ & $1 \cdot v$ & المجموع \\
\hline
\end{tabular}

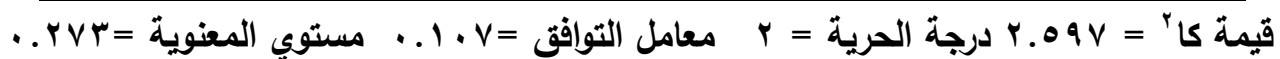
مستوي الالالة = غير دالة

تدل بيانات الجدول السابق أن نسبة الذين أكدوا أن البرامج الاستقصائية التلفزيونية تساهم في تشكيل معارف المبحوثين نحو قضية الإرهاب بلغت . . 1\% من إجمالي عينة مشاهدي

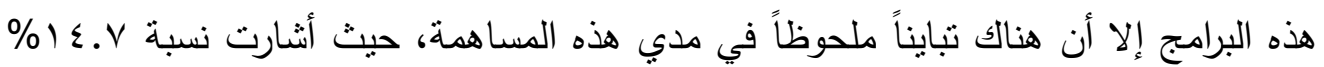
أن هذه البرامج تساهم بصفة دائمة في تشكيل معارفهم نحو فضية الإرهاب، بينما ذكرت نسبة \% \% أن هذه البرامج تساهم إلي حد ما في تتكيل معارفهم نحو فضية الإرهاب، بينما

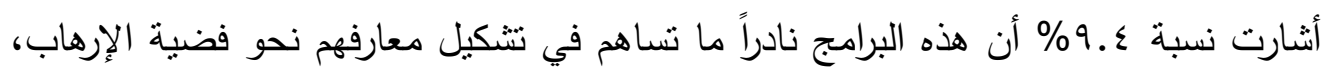

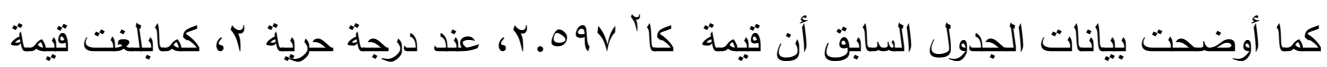

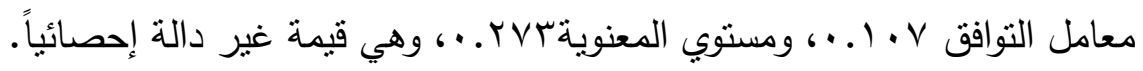


تأثير برامج الصحافة الاستقصائية التلفزيونية على معارف الثباب الجامعي نحو قضية الإرهاب.

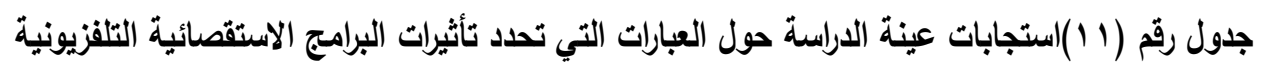

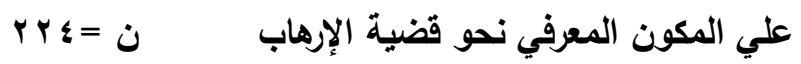

\begin{tabular}{|c|c|c|c|c|c|c|c|c|c|}
\hline \multicolumn{2}{|c|}{ الوزن المرجح } & \multicolumn{2}{|c|}{ غير موافق } & \multicolumn{2}{|c|}{ موافق إلي حد ما } & \multicolumn{2}{|c|}{ موافق بشدة } & \multirow{2}{*}{\multicolumn{2}{|c|}{ العبارة }} \\
\hline الوزن المئوي & النقاط & $\%$ & ك5 & $\%$ & ك5 & $\%$ & ك5 & & \\
\hline$V V . V$ & Ort & T.V & 10 & or.l & 119 & $\varepsilon \cdot r$ & 9. & والأحدريئة في نتـاول مختلف القضايا & \\
\hline vi.r & $\varepsilon \wedge$. & $\wedge .0$ & 19 & $\uparrow \wedge . \wedge$ & $10 \leqslant$ & rT.A & 01 & 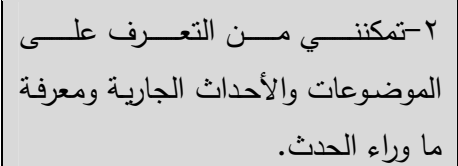 & \\
\hline (ז.ז & $\varepsilon r\}$ & TV.T & आ) & $00 . \varepsilon$ & Irs & $1 V . \varepsilon$ & rq & 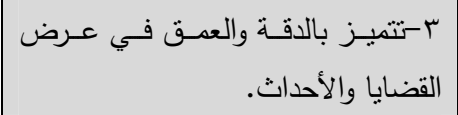 & \\
\hline$v \cdot . r$ & $\sum V Y$ & $1 \leq . r$ & r & $7 . . V$ & 4r & ro & 07 & ع الجمهور ومصالحهم القضايا والأحداث التي تمس & \\
\hline $70 . \mathrm{V}$ & $\varepsilon \varepsilon 1$ & 19.7 & $\varepsilon \varepsilon$ & ר.А & $1 \leqslant r$ & 17.0 & $r v$ & 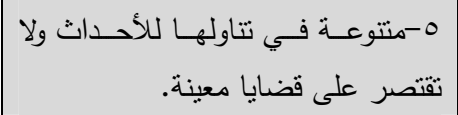 & \\
\hline TV & $\leqslant 01$ & r) & $\varepsilon V$ & $07 . V$ & ITV & Tt.T & 0 . & قضية الإرهاب. & \\
\hline TV.V & $\leqslant 0 \leqslant$ & 19.7 & $\varepsilon \varepsilon$ & $0 \wedge$ & ז. & Tr.r & 0. & 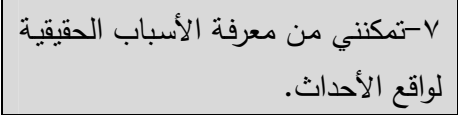 & \\
\hline TV & $\leq 01$ & $1 \wedge .1$ & $\leq r$ & $71 . r$ & ITV & $r \cdot . l$ & $\leq 0$ & وخذابة. رجرق تقديم التقارير والتحقيقات مثيرة & $\overline{7}$ \\
\hline Tr.V & $\varepsilon r \wedge$ & $r . . \varepsilon$ & $\uparrow \wedge$ & $\varepsilon \wedge . r$ & $1 \cdot 1$ & r..乏 & $\varepsilon \wedge$ & 1-تحرص على عرض القضايا السلبية فقط. & \\
\hline 74.1 & $\varepsilon \varepsilon V$ & 19.7 & $\varepsilon \varepsilon$ & $T . Y$ & irv & $19 . r$ & $\varepsilon r$ & 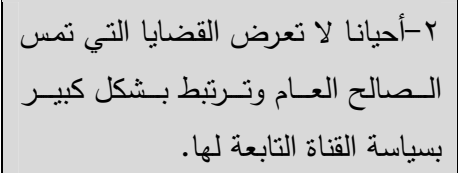 & \\
\hline TV & $\leqslant 01$ & $r \cdot . l$ & $\leq 0$ & $0 \wedge .0$ & |r & r..乏 & $\varepsilon \wedge$ & من غ-نركز على القضايا السياسية أكثر & \\
\hline TA. & $\leqslant 09$ & 18.9 & $\varepsilon$. & $09 . \varepsilon$ & سזו & Tr.A & 01 & عــتــــى مـن بعـض القـصور فـي & \\
\hline$v$. & $\leq v 1$ & iv & rᄉ & 00.1 & ro & rV.r & 71 & والخبرة. & F. \\
\hline \multicolumn{8}{|l|}{$090 \leqslant$} & مجموع الأوزان & \\
\hline
\end{tabular}


يوضح الجدول السابق العبارات التي تحدد تأثنرات البرامج الاستقصائية التلفزيونية علي المكون المعرفي لتشكيل معارف أفراد العينة نحو قضية الإرهاب والتي جاءت طبقاً لما أحرزته من تكرارات وأوزان مايلي، جاءت عبارة "جريئة في تتاول مختلف القضايا والأحداث" في

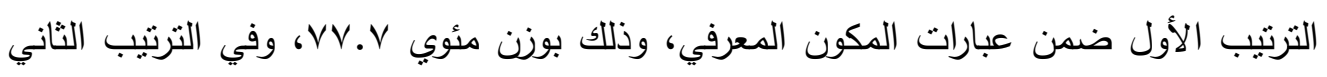

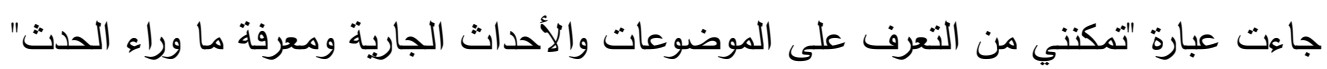
في الترتيب الأول ضمن عبارات المكون المعرفي، وذلك بوزن مئوي س.الا، وجاء في الترتيب

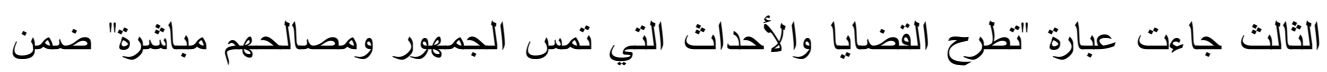
عبارات المكون المعرفي؛ وذللك بوزن مئوي r. •V، يلية في الترتيب الرابع عبارة" مقدموها

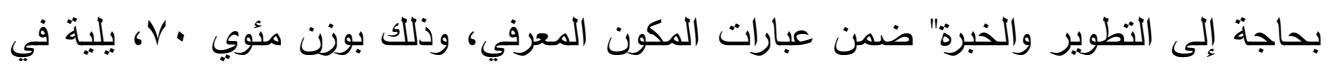
الترتيب الخامس عبارة " تعانى من بعض القصور في المهنية" ضمن عبارات المكون المعرفي،

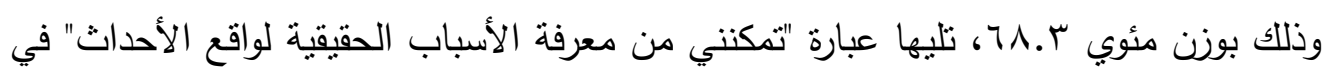
الترتيب السادس ضمن عبارات المكون المعرفي، وذلك بوزن مئوي V.TV، جاءت عبارات "تساعدني في نوسيع مداركي حول قضية الإرهاب"، " طرق تقديم التقارير والتحقيقات مثيرة

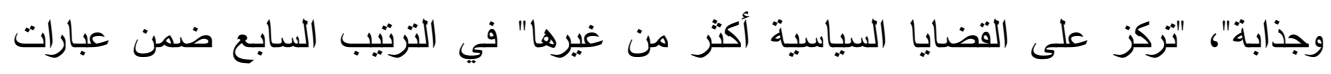

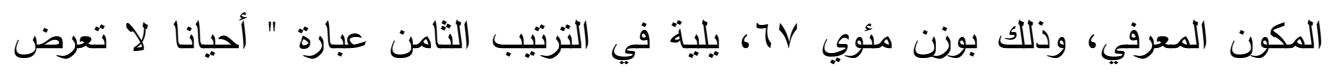
القضايا التي تمس الصالح العام وترتبط بشكل كبير بسياسة القناة التابعة لها" ضمن عبارات المكون المعرفي، وذلك بوزن مئوي ^.7 7، تليها عبارة "متتوعة في تتاولها للأحداث ولا تقتصر على قضايا معينة" في التزتيب التاسع ضمن عبارات المكون المعرفي، وذلك بوزن مئوي \.70، وجاء في الترتيب العاشر عبارة" تحرص على عرض القضايا السلبية فقط" ضمن

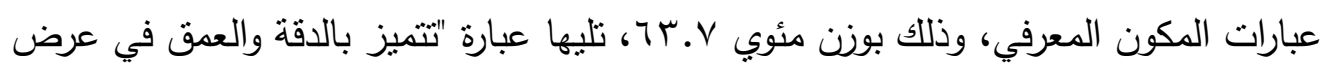
القضايا والأحداث" في الترتيب الحادي عشر ضمن عبارات المكون المعرفي، وذلك بوزن بـن 
جدول رقم (Y I)(استجابات عينة الدراسة حول العبارات التي تحدد تأثيرات البرامج الاستقصائية التلفزيونية علي المكون الوجداني نحو قضية الإرهاب

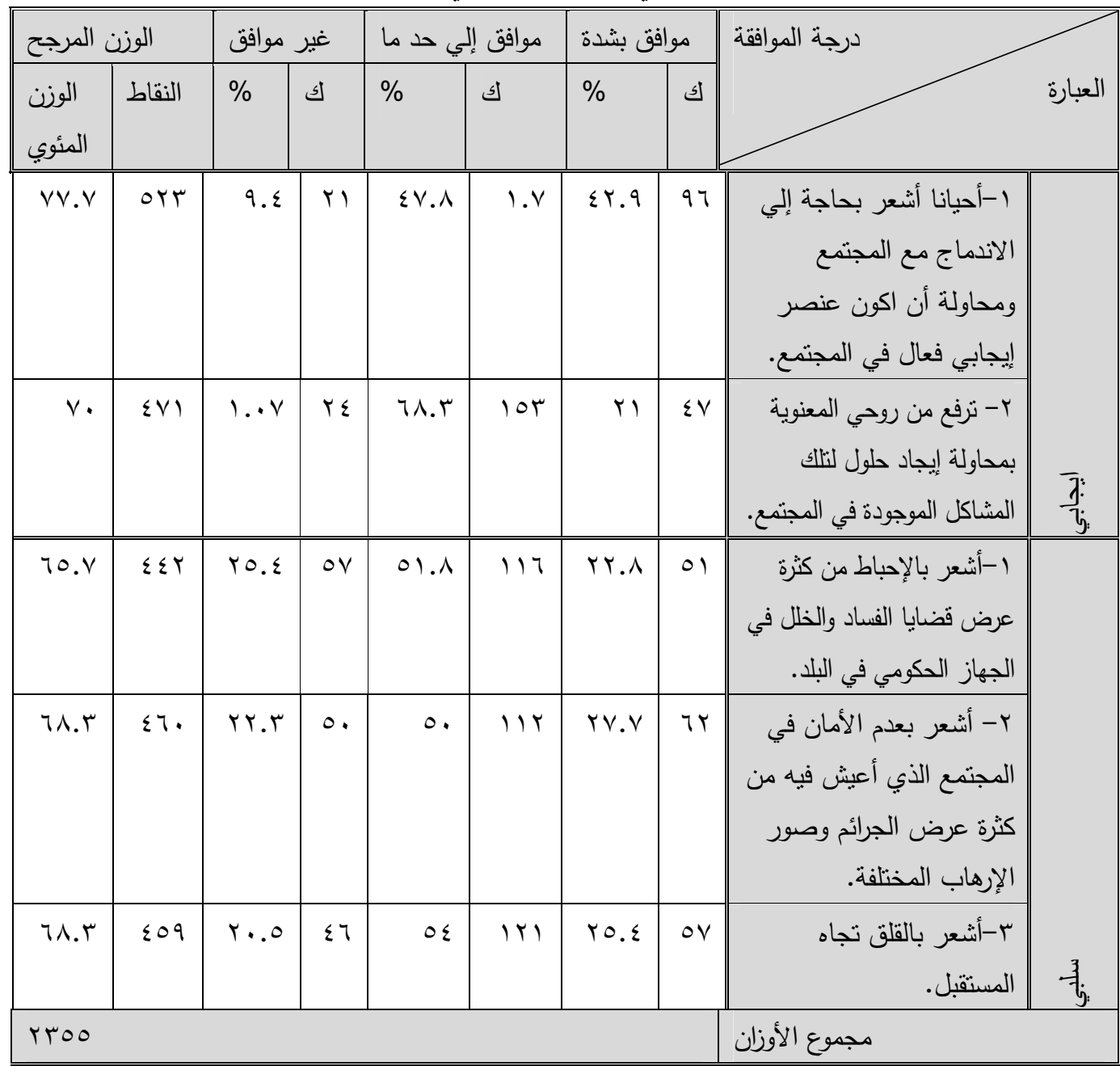

يوضح الجدول السابق العبارات التي تحدد تأثثرات البرامج الاستقصائية التلفزيونية علي الإني

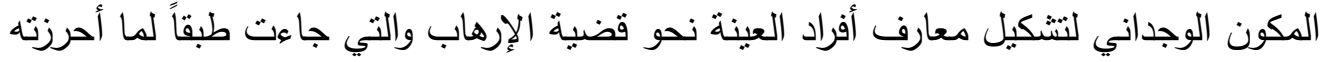

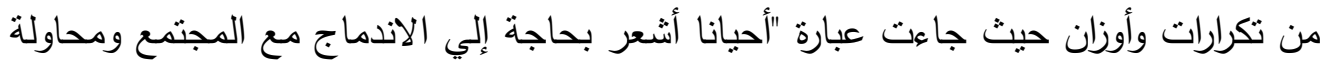

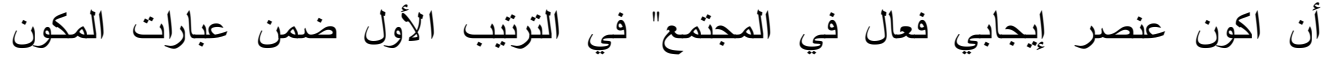

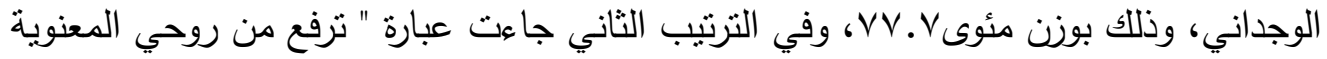

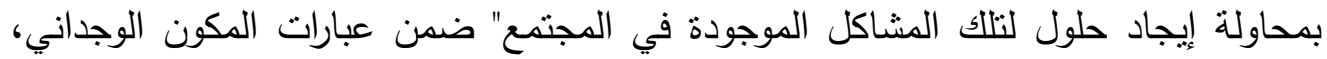

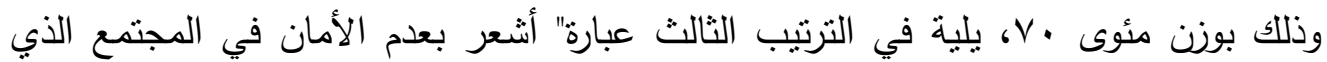

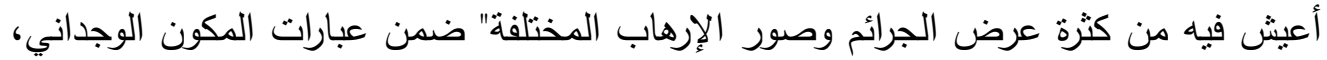

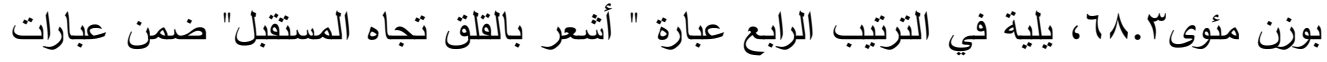


المكون الوجداني، وذلك بوزن مئوى بـ1،، تليها عبارة " أنشعر بالإحباط من كثرة عرض قضايا

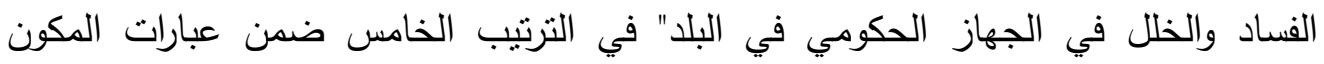

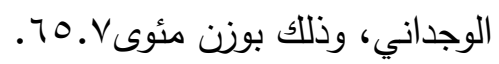

جدول رقم (r ا) استجابات عينة الدراسة حول العبارات التي تحدد تأثيرات البرامج الاستقصائية التلفزيونية علي

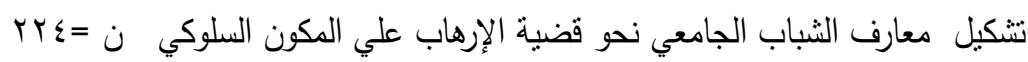

\begin{tabular}{|c|c|c|c|c|c|c|c|c|c|}
\hline \multicolumn{2}{|l|}{ الوزن المرجح } & \multicolumn{2}{|c|}{ غير موافق } & \multicolumn{2}{|c|}{ موافق إلي حد ما } & \multicolumn{2}{|c|}{ موافق بشدة } & \multirow[t]{2}{*}{ الموافقة } & \multirow[b]{2}{*}{ العبارة } \\
\hline الوزن المئوي & النقاط & $\%$ & 5) & $\%$ & 5 & $\%$ & 5) & & \\
\hline $79 . r$ & $\leq 7 \vee$ & IV & ra & $0 V .7$ & 149 & ro. & ov & 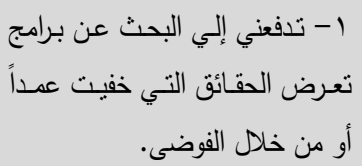 & \\
\hline$T V . r$ & sor & $1 \wedge .1$ & $\varepsilon r$ & $7 . r$ & 1ro & r) & $\leqslant V$ & ح ح-تدفعني إلي توعية الثباب ومن & \\
\hline 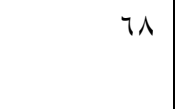 & $\{0 \wedge$ & 19.5 & $\varepsilon r$ & or.l & IrA & rT.V & or & بالاطلاع حولعني إلـي القـراءة والبحث & \\
\hline 77 & $\varepsilon \varepsilon \leqslant$ & Tr.t & or & $00 . \varepsilon$ & IrE & YI. & $\varepsilon \wedge$ & 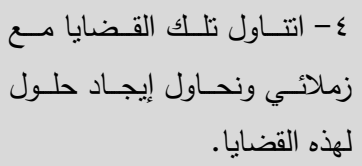 & $\begin{array}{l}\bar{j}: \\
\bar{y}:\end{array}$ \\
\hline $70 . V$ & $\varepsilon \leqslant r$ & r.. & 09 & 0 . & 114 & rT.V & or & 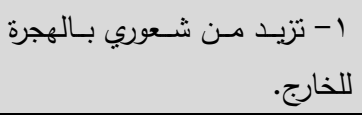 & \\
\hline $70 . r$ & $\varepsilon \varepsilon$. & ro.9 & 01 & 01.1 & 117 & Tr.T & 0. & 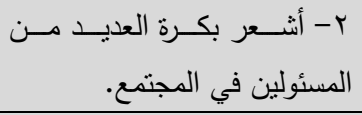 & $z_{j}$ \\
\hline \multicolumn{8}{|l|}{$r V \cdot \varepsilon$} & \multicolumn{2}{|l|}{ مجموع الأوزان } \\
\hline
\end{tabular}

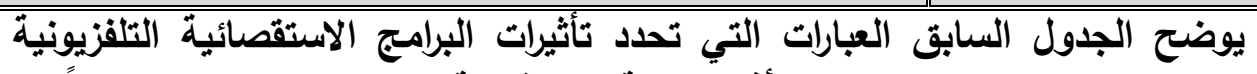

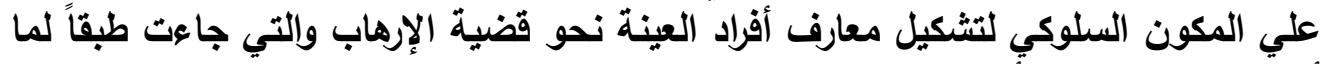

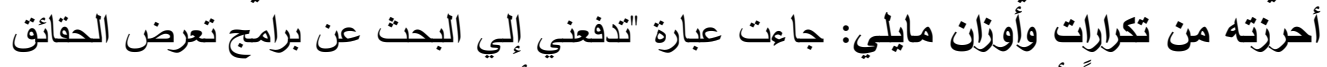

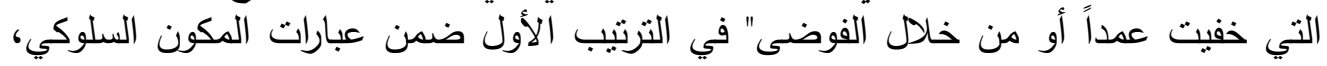

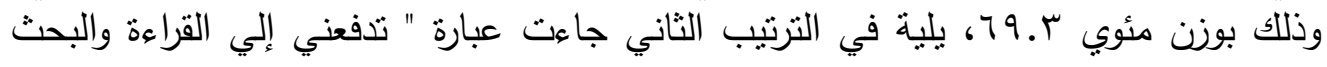

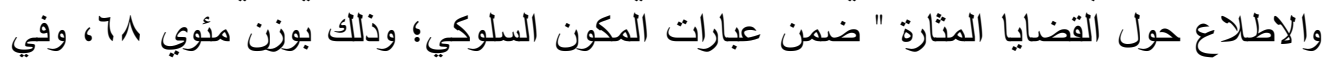

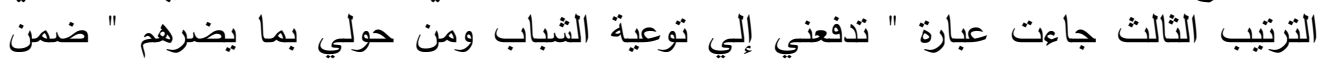

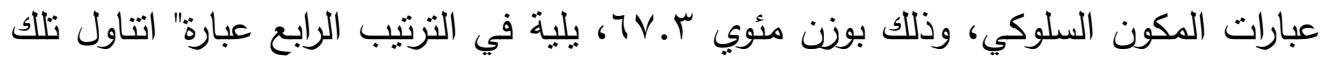

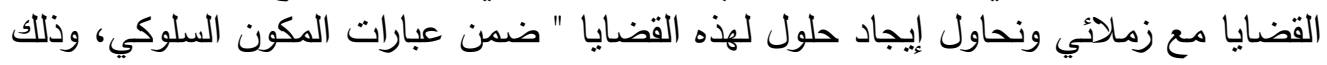

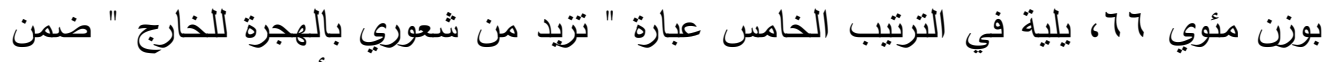

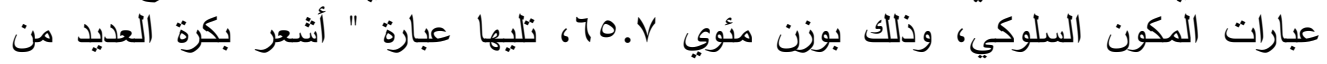

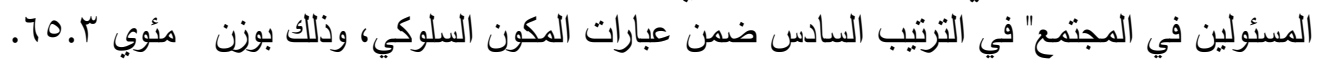




\section{النتائج العامة للاراسة:}

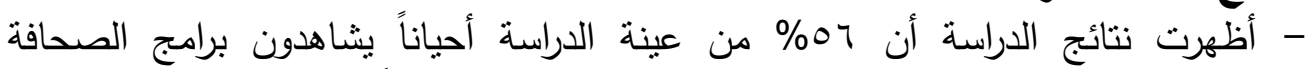

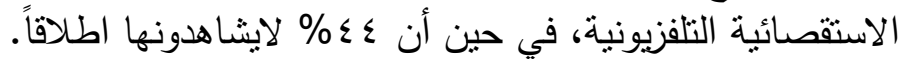

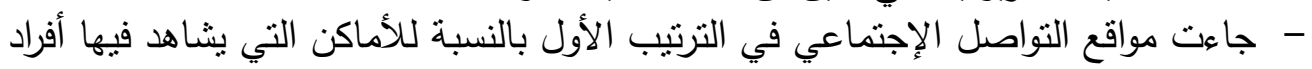

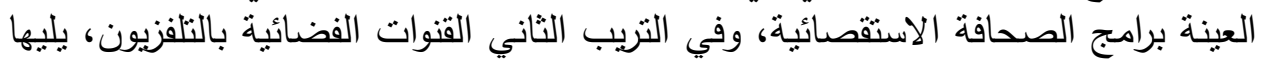
في الترتيب الثالث المواقع الإخبارية للقنوات التلتفيونية.

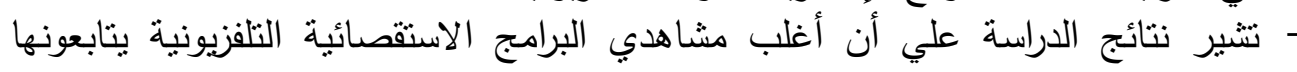
بصفة غبر منتظمة.

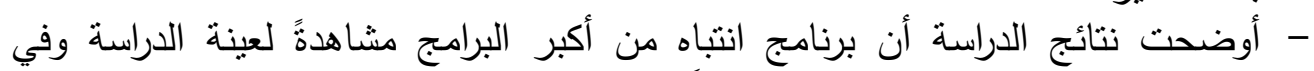

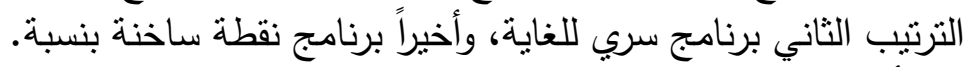

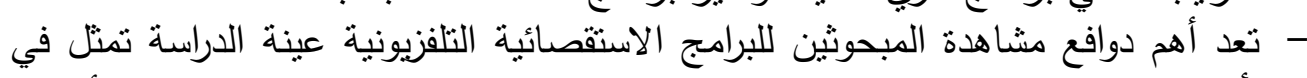

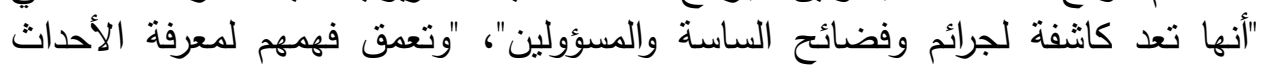

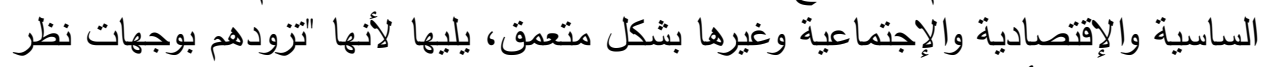

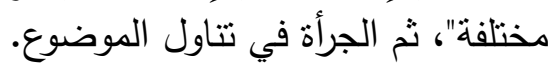

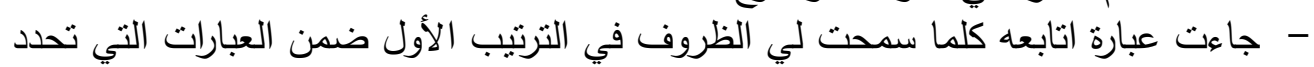

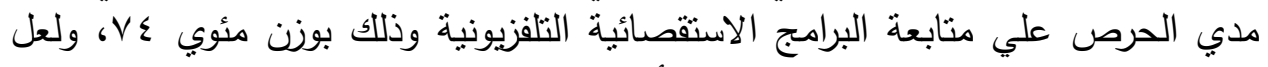

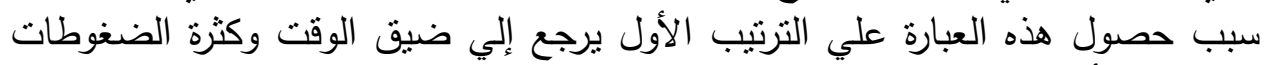

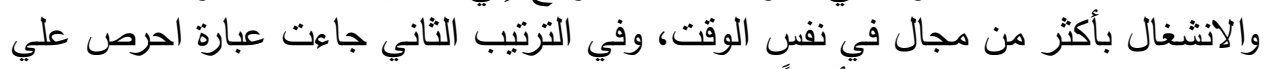

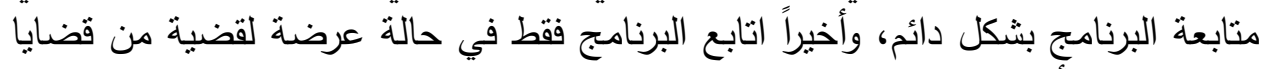
الإرهاب التي أريد متابعتها.

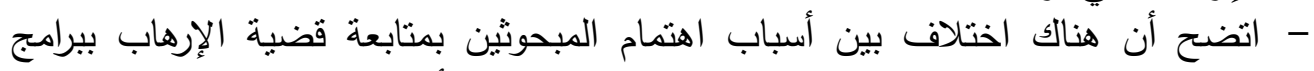

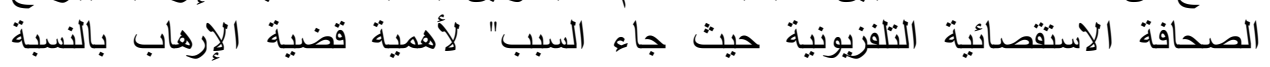

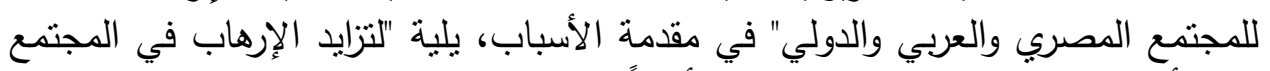

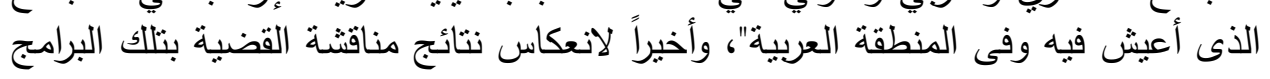

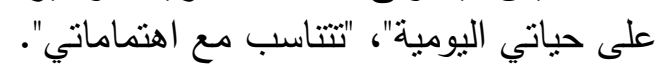

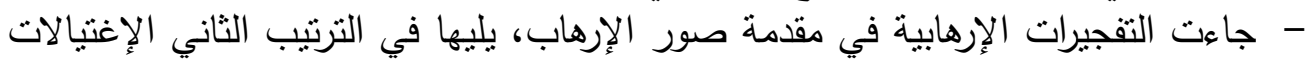

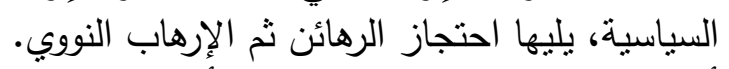

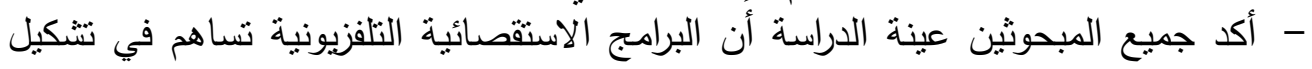
معارف المبحوثين نحو قضية الإرهاب.

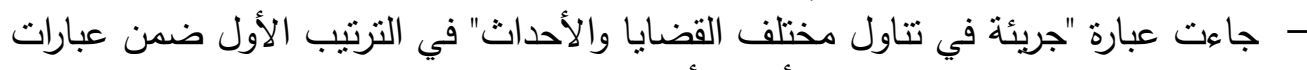

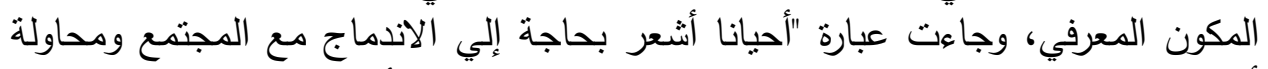

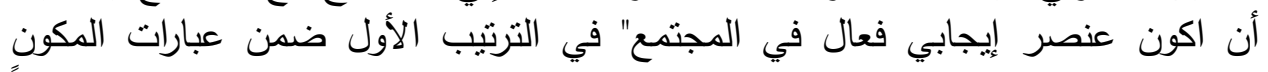

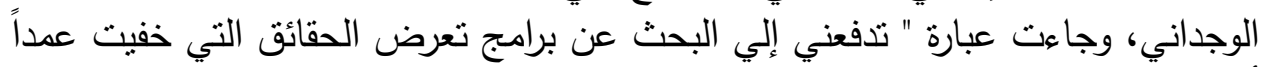

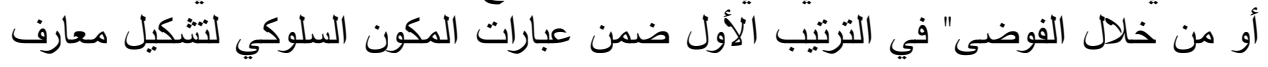
الثباب الجامعي نحو قضيية الإرهاب. 


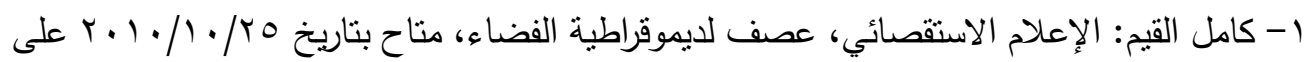

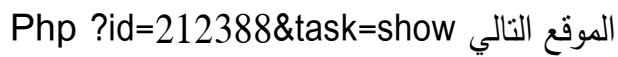

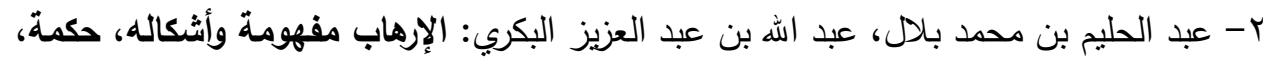

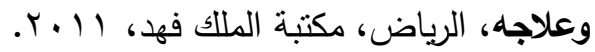

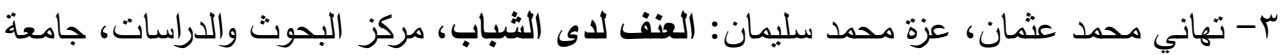

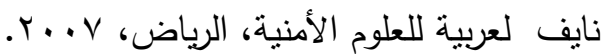

(4)Gang Han, Xiuli Wang\& Pamela shoemaker: News probe: News Farmes and Investigive Journalism in transitional china,1996-2005 paper presented the annual meeting of the international communication association, TBA, San Francisco, CA, May23, 2007, Retrieved from: http://www.alacademic.com/meta/p168759-index.html.

(5)Michael Beadet: Airing out the local T.V News Industry's own Dirty Laundry, Why are some Investigative reports Consered or Killed?, unpublished thesis Master of Arts (M.A), the school of journalism, Northeastern university- Boston, Massachusetts, 2008.

(6)Adibah Ismail, Mohd Khairie Ahmed, Che Su Mustafa: Conceptualization of Investigative Journalism: The Perspectives of Malaysian Media Practitioners, Paper Presented to The International Conference on Communication and Media, 18-20 October, Langkawi, Malaysia,2014.

(V) سارة محمود مصطفي الحطيبي: أساليب الصحافة الاستقصائية التلفزيونية ودورها في معالجة

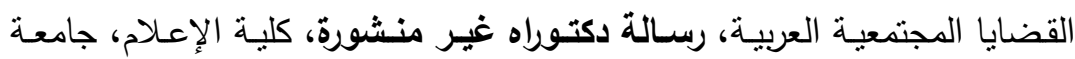

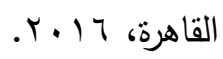

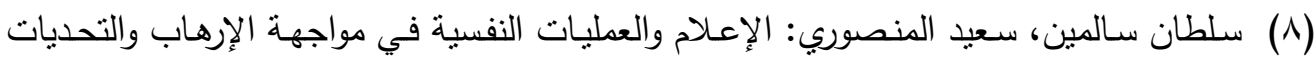

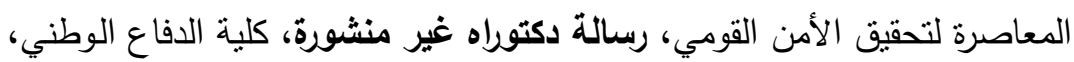

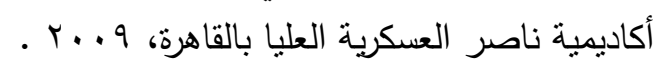

(9) Mamdoh Al-Ameri: Media and USF Students, Perception of Terrorism, degree of Master of Arts, college of Arts and Sciences, University of South Florida, 2013.

(10) Greg Blackburn: Television viewing and the cultivation of terrorism, 2014, On line on http://research.allacaademic.com/2014, preparedness 6/1/2015.

(1) هبـة شـاهين: المسؤولية الاجتماعيـة والأمنيـة لوسـائل الإعـلام في تنـاول قضية الإرهـاب،

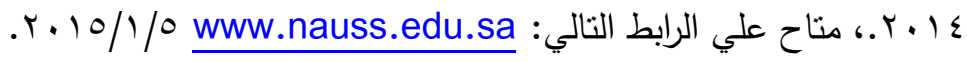

(12)Daniel J. Boches: what is terrorism? Social geometry and the media labeling of political violence, Master of arts, Bachelor of Arts, University of New Hampshire, 2016. 
(rا) هالة إبراهيم درويش: إدراك عينة من الثباب الجامعي لبعض الدفاهيم السياسية من خلال

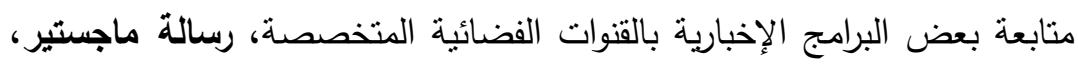

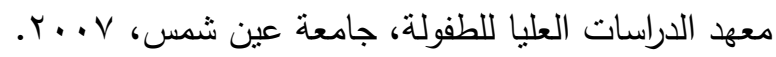

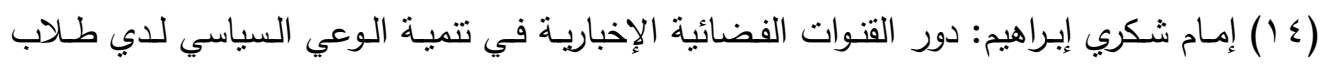

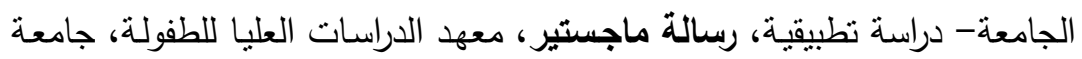

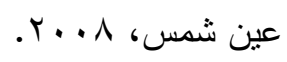

(10) فاتن عبد الرحمن الطنبارى، هالة حمدي حسن، إيناس محمود : دوافع تعرض الثباب الجامعي

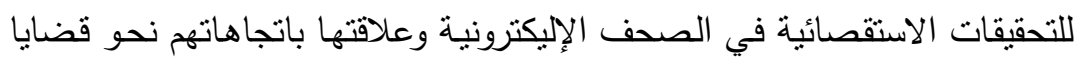

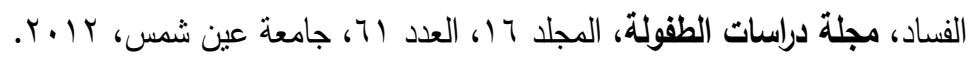

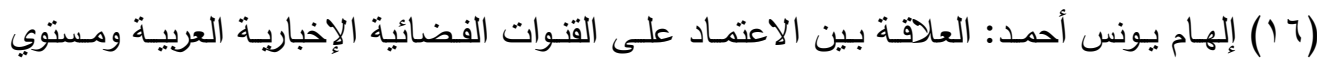

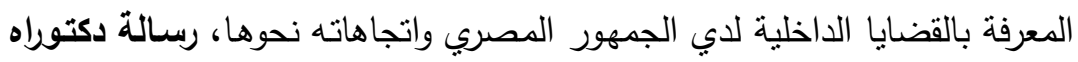

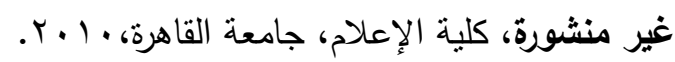

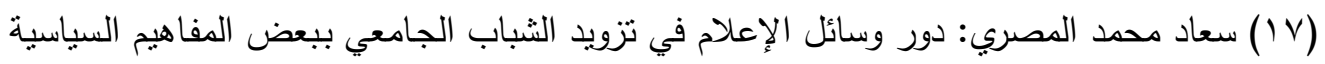

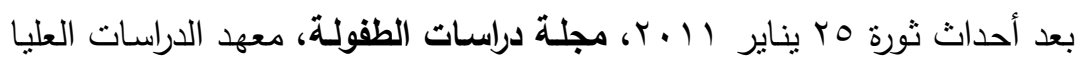

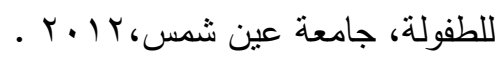

